\title{
Prolyl-hydroxylase 3: evolving roles for an ancient signaling protein
}

\author{
Trenton L Place' \\ Frederick E Domann ${ }^{1,2}$ \\ 'Molecular and Cellular Biology \\ Program, the University of lowa, \\ lowa City, IA, USA; ' ${ }^{2}$ epartment \\ of Radiation Oncology, the University \\ of lowa, lowa City, IA, USA
}

\author{
This article was published in the following Dove Press journal: \\ Hypoxia \\ 15 October 2013 \\ Number of times this article has been viewed
}

Correspondence: Frederick E Domann BI 80 Medical Laboratories, the University of lowa, lowa City, IA, USA 52242-I I8I $\mathrm{Tel}+\mathrm{I} 3193358019$

Fax +I 3193358039

Email frederick-domann@uiowa.edu

\begin{abstract}
The ability of cells to sense oxygen is a highly evolved process that facilitates adaptations to the local oxygen environment and is critical to energy homeostasis. In vertebrates, this process is largely controlled by three intracellular prolyl-4-hydroxylases (PHD) 1-3. These related enzymes share the ability to hydroxylate the hypoxia-inducible transcription factor (HIF), and therefore control the transcription of genes involved in metabolism and vascular recruitment. However, it is becoming increasingly apparent that PHD controls much more than HIF signaling, with PHD3 emerging as an exceptionally unique and functionally diverse PHD isoform. In fact, PHD3-mediated hydroxylation has recently been purported to function in such diverse roles as sympathetic neuronal and muscle development, sepsis, glycolytic metabolism, and cell fate. PHD3 expression is also highly distinct from that of the other PHD enzymes, and varies considerably between different cell types and oxygen concentrations. This review will examine the evolution of oxygen sensing by the HIF family of PHD enzymes, with a specific focus on the complex nature of PHD3 expression and function in mammalian cells.
\end{abstract}

Keywords: PHD3, EGLN3, HIF-PHD, hypoxia-inducible factor, hypoxia, oxygen sensing

\section{Introduction}

Molecular oxygen $\left(\mathrm{O}_{2}\right)$ : nothing has shaped our planet more than this simple molecule. Its first appearance in significant quantities occurred nearly 2.5 billion years ago as a product of cyanobacteria photosynthesis in Earth's expansive seas. ${ }^{1-3}$ Over the next 2 billion years, a "Great Oxygenation Event" occurred. This accumulation of $\mathrm{O}_{2}$ in the atmosphere stimulated the evolution of more highly efficient aerobic respiration. It also necessitated the evolution of antioxidant systems, as $\mathrm{O}_{2}$ is a highly reactive and potentially damaging molecule. Ultimately, the result was the appearance of a complex signaling system for sensing and controlling $\mathrm{O}_{2}$ usage within the cell, allowing organisms to balance the life-giving yet poisonous properties of $\mathrm{O}_{2}$.

The foundation for this evolutionary feat began with the origin of a prolyl-4hydroxylase (PHD) enzyme, which was likely spurred by the initial appearance of $\mathrm{O}_{2}$. This happened sometime before the divergence of amoebozoa (Dictyostelium discoideum) from other eukaryotes around 2 billion years ago (Figure 1). ${ }^{46}$ By utilizing $\mathrm{O}_{2}$ as a substrate for posttranslational modification of signaling proteins, this primitive PHD allowed the integration of environmental signals (for example, fluctuating $\mathrm{O}_{2}$ concentrations) with cell signaling pathways that control critical events in the lifecycle of these organisms. ${ }^{5,6}$ Around 800 million years ago, atmospheric $\mathrm{O}_{2}$ levels rose even more considerably, and organisms began to utilize and transport $\mathrm{O}_{2}$ in more complex ways. In the animal kingdom (metazoans), a hypoxia-inducible transcription factor 


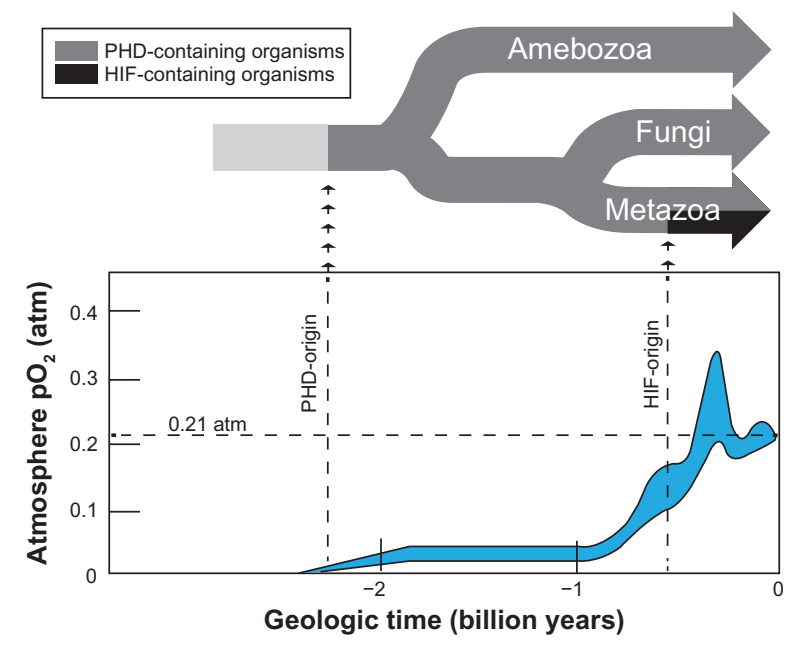

Figure I The evolution of PHD and HIF in relation to the oxygenation of Earth. Notes: At the top of the figure, the phylogenetic tree of the PHD-containing groups amebozoa and opisthokonta (metazoan and fungi) (5) $^{5}$ is depicted with approximate branch points relative to the Earth's geological age. The arrows indicate the approximate origins of the PHD and HIF genes. ${ }^{4,7,86}$ At the bottom of the figure, the partial pressure of atmospheric $\mathrm{O}_{2}$ is graphed in relation to time, as adapted from Holland et al. ${ }^{3}$ The gray area represents the range of the estimate. ${ }^{3}$ In addition, 0.2 I atm (the current $\mathrm{PO}_{2}$ ) is marked as a dotted line. Holland HD. The oxygenation of the atmosphere and oceans. Philos Trans R Soc Lond B Biol Sci. 2006;36 I (1470):903$915^{3}$, by permission of the Royal Society.

Abbreviations: PHD, prolyl-4-hydroxylase; HIF, hypoxia-inducible transcription factor; $\mathrm{PO}_{2}$, partial pressure of oxygen.

(HIF) evolved, which integrated $\mathrm{O}_{2}$-sensing (PHD) ability with control of blood cell production, vascular recruitment, and metabolism. ${ }^{1}$ It was later during the evolution of vertebrate metazoans that the single $P H D$ gene split into three independent cytoplasmic PHD enzymes (PHD 1-3). ${ }^{7}$ Overall, these events enabled the evolution of large, complex organisms with exquisite integration of $\mathrm{O}_{2}$ sensing, $\mathrm{O}_{2}$ delivery, metabolism, and other critical cellular processes. ${ }^{1}$

The temporal relationship between PHD and HIF evolution is often overlooked, as the literature commonly focuses on HIF pathway regulation when discussing PHD function. Nonetheless, PHD enzymes predate metazoans and, therefore, HIF evolution. This fact strongly implies that the roots of the PHD-mediated $\mathrm{O}_{2}$ sensing system run much more deeply within the cell signaling machinery than simple control of the HIF pathway. A recent increase in the identification of non-HIF PHD targets seems to validate this assumption, with PHD3 leading the way with its broad involvement in cell survival, differentiation, metabolism, and cell migration. The following review will provide a brief overview of the expression and function of the HIF-PHD enzymes, and will then focus on PHD3 and evidence for its broad functionality.

\section{The metazoan HIF-PHD family}

PHD3 (PHD3/EGLN3/SM-20) is one of three cytoplasmic Fe-2-dependent PHDs (PHD1/EGLN2; PHD2/EGLN1; and PHD3/EGLN3/SM-20) that hydroxylate HIF- $\alpha$ subunits at two conserved proline residues. Along with their requirement for $\mathrm{Fe}-2$, these enzymes consume molecular $\mathrm{O}_{2}$ and 2-oxolglutarate (2-OG), yielding succinate, $\mathrm{CO}_{2}$, and a 4-hydroxylated proline residue (Figure 2). The mammalian genome also encodes for two multi-subunit collagen PHD enzymes and an endoplasmic reticulum membrane-associated PHD (P4H-TM) that is capable of HIF hydroxylation. ${ }^{8,9}$ Although these other PHDs are related to the HIF-PHDs in their requirement for $\mathrm{O}_{2}, 2-\mathrm{OG}$, and $\mathrm{Fe}-2$, they are localized to the endoplasmic reticulum and share little sequence homology with the HIF-PHDs. ${ }^{9}$ Therefore, further discussion of PHD enzymes will be in reference only to HIF-PHD 1, 2, and 3.

\section{Effectors of PHD enzymatic activity}

Examination of the enzymatic mechanism of the PHDs uncovers an elegant design that is simultaneously sensitive to $\mathrm{O}_{2}$ concentration, tricarboxylic (TCA) cycle disturbances, and redox status within the cell. The sensitivity of the PHDs to these parameters is notable in the context of severe disturbances of metabolism and oxidative stress, which often present as abnormal accumulation of HIF proteins.

\section{TCA cycle/metabolism}

Errors in metabolism are well known in activating the $\mathrm{O}_{2}$-sensing pathways of the cell. This is due to the unique sensitivity of the PHD enzymatic mechanism to components of cellular metabolism. Molecular $\mathrm{O}_{2}$ itself is consumed directly in the hydroxylation reaction, with one $\mathrm{O}_{2}$ atom becoming incorporated into the hydroxyl group on the receptive proline residue. ${ }^{10}$ Concurrently, 2-OG from the TCA cycle undergoes oxidative decarboxylation to succinate (see Figure 2). ${ }^{10}$

This exquisite sensitivity of the PHDs to cellular metabolism is observable in the context of numerous benign and malignant tumors containing mutations in TCA cycle enzymes. These include inactivating mutations in succinate dehydrogenase in paragangliomas and pheochromocytomas, and fumarate hydratase leiomyoma and renal cancer. ${ }^{11}$ Furthermore, gain-of-function mutations in isocitrate dehydrogenase (IDH) $1 / 2$ in acute myeloid leukemia and gliomas have also been shown to result in activation of the HIF pathway. ${ }^{12}$

The mechanism for HIF activation in the presence of these mutations is thought to be due to the accumulation of metabolic intermediates. For example, mutations in fumarate hydratase and succinate dehydrogenase lead to the accumulation of fumarate and succinate, respectively, which likely 


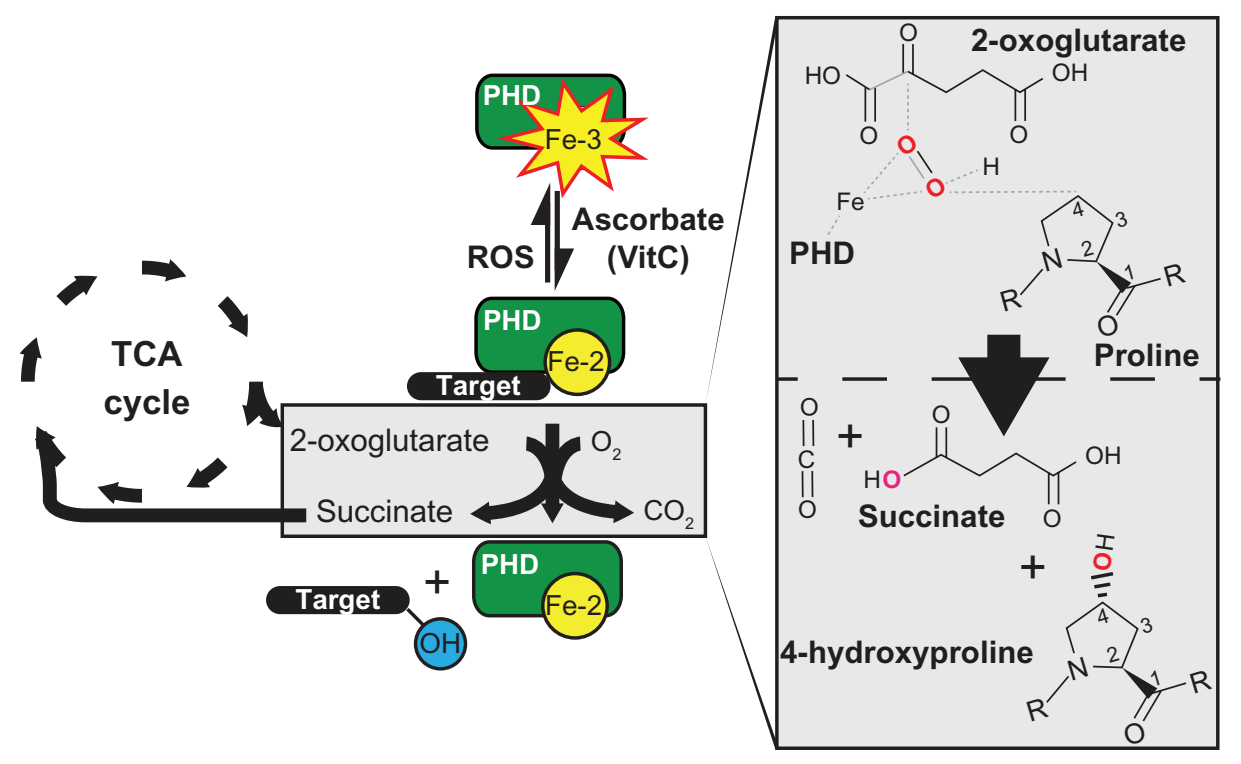

Figure 2 The interaction between metabolism and PHD enzymatic activity.

Notes: It is apparent that 2-oxoglutarate from the TCA cycle is utilized, along with molecular oxygen, to hydroxylate a proline residue on carbon 4 . The reaction produces $\mathrm{CO}_{2}$ and succinate (left). Hydroxylation is thought to involve a transient $\mathrm{OOH}$ molecule, which is stabilized by Fe-2 in the PHD3 catalytic domain. One oxygen atom subsequently becomes incorporated into succinate, and the other in the proline- $\mathrm{OH}$ group (right). During oxidative stress, Fe- 2 is susceptible to oxidation by reactive oxygen species, which inhibits hydroxylase activity. Fe 3 is reduced back to Fe-2 by ascorbate/Vit C.

Abbreviations: TCA, tricarboxylic; PHD, prolyl-4-hydroxylase; Vit, vitamin; ROS, reactive oxygen species; OH, hydroxyl group.

act through product inhibition of the active site of PHD. ${ }^{11,13}$ Mutations in IDH, on the other hand, promote the abnormal production of (R)-2-hydroxyglutarate (2-HG). It should be noted that $2-\mathrm{HG}$ is similar in structure to $2-\mathrm{OG}$, but is not an appropriate substrate for oxidative decarboxylation. Similarly, dimethyloxalylglycine is a synthetic 2-OG analog used in cell culture to inhibit PHD activity, and likely works through a similar mechanism of action (see Figure 3 ).

\section{Redox state}

Another layer of PHD enzymatic regulation occurs due to PHD inactivation by reactive oxygen (ROS) species (see Figure 2). ${ }^{14}$ This is due to the sensitivity of Fe-2 to oxidation by ROS. ${ }^{14}$ Oxidized iron (Fe-3) is not compatible with PHD enzymatic activity, resulting in increased stability of HIF. ${ }^{15}$ The effect of ROS on HIF stability is well documented in many conditions where mitochondrial function is compromised. This may occur, in part, to a premature leak of electrons from complexes 1 and 3 of the electron transport chain (ETC), which results in superoxide production $\left(\mathrm{O}_{2}^{-}\right) .{ }^{16}$ This $\mathrm{O}_{2}^{-}$is dismutated to $\mathrm{H}_{2} \mathrm{O}_{2}$ by manganese superoxide dismutase, and ultimately results in PHD inactivation by the mechanism described above (see Figure 3). ${ }^{17,18}$

This reliance of PHDs on Fe-2 explains the role of ascorbate/vitamin $\mathrm{C}$ in proline hydroxylation. Ascorbate promotes the reduction of $\mathrm{Fe}-3$ to $\mathrm{Fe}-2$, and is therefore able to recover PHD enzymatic activity in the event of
Fe-2 oxidation. ${ }^{19}$ This is the mechanism for the phenotype observed in physiologic ascorbate deficiency (scurvy), where collagen PHDs become dysfunctional due to the inability to replenish Fe-2. ${ }^{20}$ Although all PHDs apparently share the same mechanism of action, ${ }^{21}$ it is unclear if the HIF-PHDs are affected in this particular pathologic state. Nonetheless, a lack of ascorbate in cell culture media has been attributed to aberrancies in the HIF pathway in vitro. ${ }^{22,23}$

Other conditions where intracellular iron pools are compromised or rendered unavailable to PHDs also inhibit PHD activity. This is the basis for the usage of the iron chelating agent desferrioxamine in experiments involving $\mathrm{O}_{2}$-sensing pathways. Cobalt (Co-2) is also used as an in vitro PHD inhibitor, presumably through competition with Fe-2 in the active site (see Figure 3 ). ${ }^{24}$

\section{PHD structure}

Amino acid residues within the human PHD3 catalytic domain are highly conserved with that of PHD1 and 2; however, N-terminal sequences are highly divergent. In fact, the PHD3 N-terminus is over 150+ amino acids shorter in length than both PHD1 and PHD2 (Figure 4). This suggests that N-terminal residues dictate the functional diversity of the PHD enzymes. Among other vertebrates, sequence variation within individual PHD isoforms is generally minimal. However, there is a notable exception with rat PHD3, which differs significantly from other vertebrate PHD3 sequences 


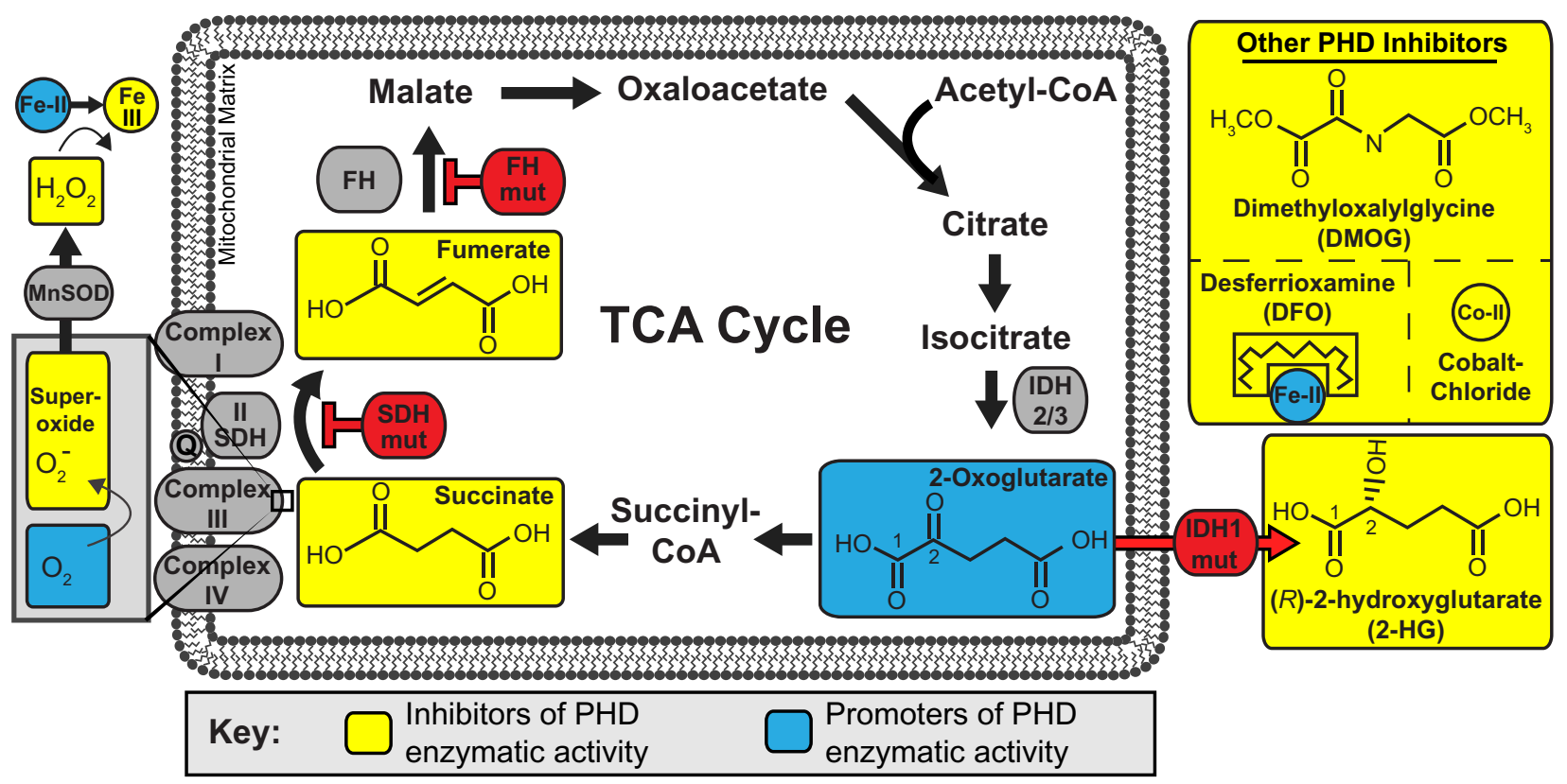

Figure 3 Effectors of PHD3 enzymatic activity.

Notes: Proline hydroxylation requires 2-oxoglutarate from the TCA cycle, and $\mathrm{O}_{2}$ for enzymatic function (blue boxes). The TCA cycle and electron transport chain are the source of many inhibitors of PHD enzymatic activity (yellow boxes). Build-up of fumarate occurs upstream of FH-mut and succinate buildup occurs upstream of SDH-mut. Gain-of-function mutations in the IDHI-mut produce (R)-2-hydroxyglutarate, another PHD inhibitor. Electron leak from complex 3 of the electron transport chain results in superoxide production $\left(\mathrm{O}_{2}^{-}\right)$in the presence of $\mathrm{O}_{2}$, which is converted to $\mathrm{H}_{2} \mathrm{O}_{2}$ by catalase. ROS, such as $\mathrm{H}_{2} \mathrm{O}_{2}$ can oxidize Fe-2 to Fe-3. PHD inhibitors commonly used in research include dimethyloxalylglycine, desferrioxamine, and cobalt-chloride (Co-2) (upper right yellow box).

Abbreviations: MnSOD, manganese superoxide dismutase; $\mathrm{FH}$, fumarate hydratase; mut, mutations; SDH, succinate dehydrogenase; Co-2, cobalt-chloride; IDH, isocitrate dehydrogenase; IDHI, cytoplasmic isoform if isocitrate dehydrogenase; PHD, prolyl-4-hydroxylase; TCA, tricarboxylic; ROS, reactive oxygen species; OH, hydroxyl group.

by the presence of a large N-terminal region containing a mitochondrial localization sequence (Figure 3). ${ }^{25}$ This point becomes important when interpreting PHD3 data from rat studies, which make up a large portion of the PHD3 literature.

\section{PHD3 target proteins}

The PHD family's conserved PHD activity targets HIF- $\alpha$, and a growing list of other intracellular proteins that contain a

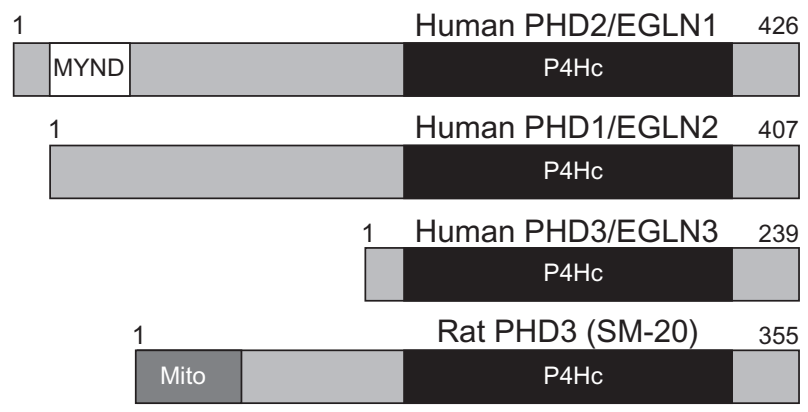

Figure 4 Models of human PHDI-3 and rat PHD3 (SM-20) proteins.

Notes: PHDI, PHD2, and three proteins all share highly homologous P4Hccontaining sequences in their $\mathrm{N}$-terminus. $\mathrm{PHD} 2$ is the longest $\mathrm{PHD}$ and contains a MYND. Rat PHD3 (SM-20) is unique in that it contains a Mito.

Abbreviations: PHD, prolyl-4-hydroxylase; EGLN, egg-laying-defective nine; MYND, C-terminal MYND-type zinc finger domain; P4Hc, prolyl-4-hydroxylase; SM-20, smooth muscle-20; Mito, N-terminal mitochondrial localization signal. conserved Leu-X-X-Leu-Ala-Pro (LXXLAP) motif, where X represents any amino acid. Early studies identified the LXXLAP motif as consensus for PHD-mediated hydroxylation. ${ }^{26}$ However, studies have shown that substitutions within the LXXLAP motif can still allow for PHD-mediated hydroxylation. ${ }^{27,28}$ Recent studies involving PHD3 have supported this by identifying putative PHD3 target proteins that are hydroxylated on prolines outside of LXXLAP motifs. ${ }^{29-31}$

Identification of these targets is a difficult hurdle to overcome when studying PHD biology. This can be attributed, in part, to the small-sized, noncharged nature of the hydroxyl modification. Nonetheless, several strategies have been published, including the use of ${ }^{14} \mathrm{C}$-labeled $2-\mathrm{OG}$ in in vitro hydroxylation assays, with the production of ${ }^{14} \mathrm{C}$-labeled $\mathrm{CO}_{2}$ as a surrogate indicator for hydroxylation. ${ }^{32} \mathrm{~A}$ hydroxyproline antibody also exists and has been utilized with limited success in cases where the hydroxylated protein is first immunoprecipitated. ${ }^{30}$ Other investigators have used liquid chromatography followed by tandem mass spectroscopy analysis of tryptic fragments from isolated proteins. ${ }^{29-31}$

Although the latter type of analysis is quite popular, it has several intrinsic problems, which may raise questions regarding some of the currently published data. First, metal present during protein processing can theoretically result in 
proline oxidation, leading to cis/trans-4-hydroxyproline. ${ }^{33}$ Also, it should be noted that leucine and isoleucine have nearly identical molecular weights to hydroxyl-proline $\left(\mathrm{P}_{\mathrm{OH}}\right)$, which could lead to misinterpretation of LXXLAL or LXXLAI as a peptide containing a LXXLAP ${ }_{\mathrm{OH}}$. These obstacles necessitate careful consideration when planning and interpreting hydroxyproline data. The use of isotope-labeled synthetic peptides containing 4-hydroxyproline as positive controls, may allow for more reliable identification of true hydroxyproline-containing peptides as the mass spectrometry ionization patterns of these synthetic peptides can be used for comparison against experimental data. Furthermore, the use of hydroxylase inhibitors should be used as controls to demonstrate the reduction of hydroxylated prolines within putative target proteins.

Upon the identification of hydroxylated prolines on target proteins, the assignment of a specific PHD as the hydroxylase responsible for this hydroxylation should also be made with care. The PHD family has previously been demonstrated to assemble into higher-order complexes composed of heteromultimeric constituents of the various PHD enzymes..$^{34}$ Coimmunoprecipitated complexes may contain several different PHDs that may be responsible for target hydroxylation. Therefore, in vitro experiments identifying direct protein-protein interactions and/or hydroxylation reactions should be performed when identifying novel PHD target proteins.

\section{Other PHD3-interacting proteins}

Aside from hydroxylation targets, PHD3 appears to have many effector proteins that have not been reported as targets for hydroxylation. This list far outweighs the list of identified PHD3 targets (for references, see Table 1). Some of these studies ruled out hydroxylation due to the absence of an effect when PHD3 was mutated at an active site histidine, or by use of a hydroxylase inhibitor. This suggests that PHD3 has hydroxylase-independent effects, and supports previous studies that suggest protein-protein complexes involving PHD3 may play significant functional roles within the cell. ${ }^{34,35}$

\section{HIF - the classic PHD target}

The first PHD targets to be recognized were HIF-1 $\alpha$ and HIF- $2 \alpha$ (collectively called HIF- $\alpha$ ). ${ }^{26}$ HIF- $\alpha$ proteins are unique basic-helix-loop-helix transcription factors that function to regulate the transcription of genes that control critical processes like metabolism, cell cycle, and vascular recruitment (there are several excellent reviews ${ }^{36-38}$ ). The key to the regulation of the HIF- $\alpha$ protein is their posttranslational

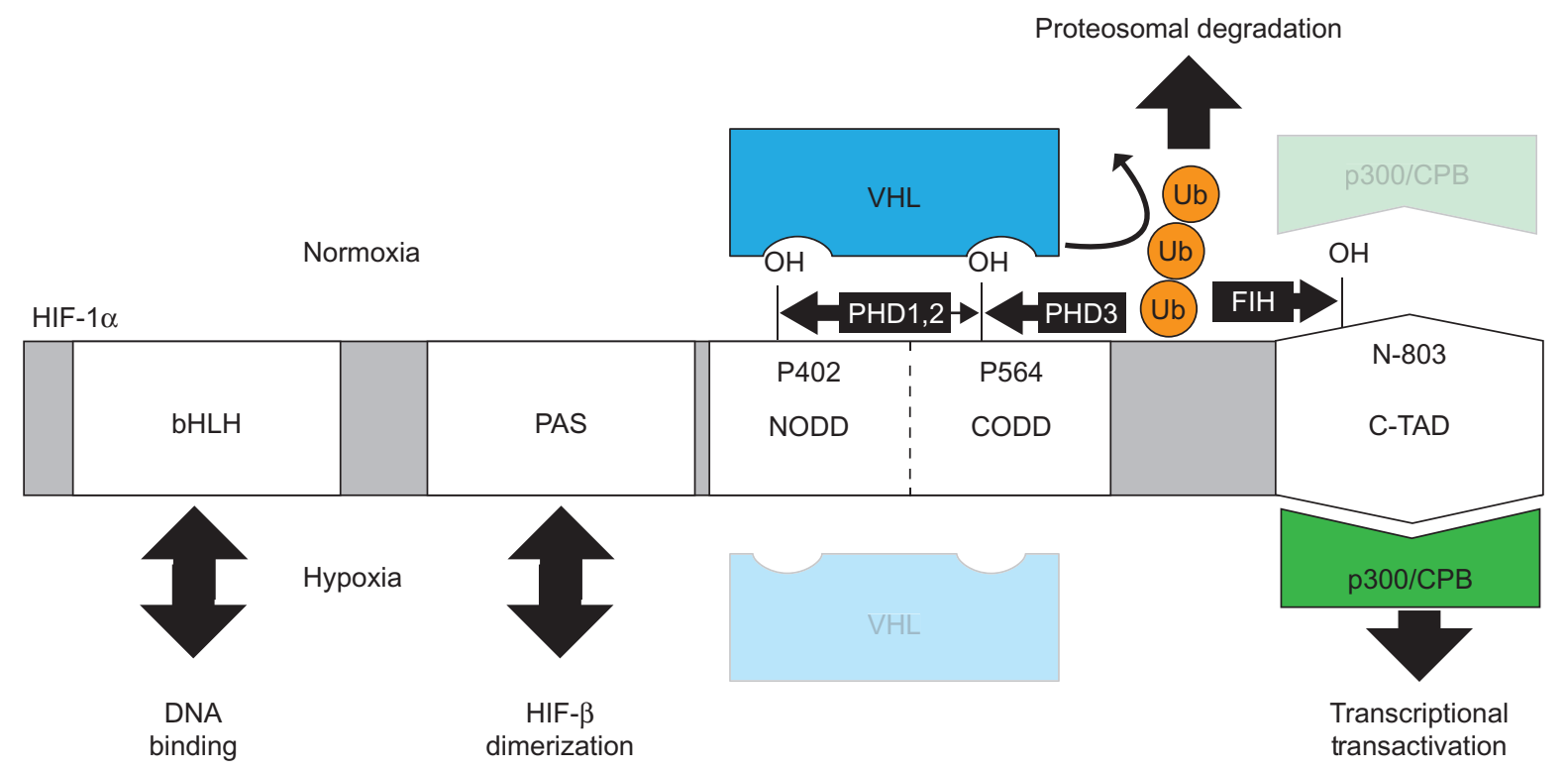

Figure 5 HIF-I $\alpha$ regulation.

Notes: In the presence of $\mathrm{O}_{2}$, HIF-I $\alpha$ is hydroxylated by PHDI, PHD2, or PHD3 on two proline residues in the $\mathrm{O}_{2}$-dependent domain. These hydroxylated proline residues serve as binding sites for VHL, which binds and Ub HIF-I $\alpha$. Hydroxylation on asparagine 803 in the C-TAD by FIH blocks p300/CPB recruitment, which further inhibits HIF transcriptional transactivation. In the absence of $\mathrm{O}_{2}$, HIF is not hydroxylated and VHL does not bind (bottom of figure). HIF-I $\alpha$ protein levels are subsequently stabilized and HIF-I $\alpha$ becomes localized to the nucleus where it dimerizes with HIF-I $\beta$ via the PAS domain and interacts with DNA through the bHLH domain. P300/CBP is recruited through binding to the C-TAD.

Abbreviations: HIF, hypoxia-inducible transcription factor; bHLH, basic helix-loop-helix; DNA, deoxyribonucleic acid; PAS, Per-aryl hydrocarbon receptor nuclear translocatorSim; VHL, Von Hippel-Lindau tumor suppressor; NODD, nonoxygen-dependent domain; CODD, C-terminal oxygen-dependent degradation domain Ub, ubiquitinates; FlH, factor-inhibiting hypoxia-inducible transcription factor; $\mathrm{OH}$, hydroxide; PHD, prolyl-4-hydroxylase, C-TAD, C-terminal activation domain; CPB, creb-binding protein. 
regulation by PHD enzymes. In the presence of $\mathrm{O}_{2}$ (normoxia), PHD enzymes quickly hydroxylate HIF- $\alpha$ subunits on two highly conserved proline residues that reside in conserved LXXLAP hydroxylation motifs in the HIF- $\alpha$ $\mathrm{O}_{2}$-dependent degradation domain (ODD). It is interesting to note here that PHD 1-3 have different affinities for either the N-terminal ODD (NODD) proline or the C-terminal ODD (CODD) proline of HIF- $\alpha .{ }^{39,40}$ PHD3 almost exclusively hydroxylates the CODD, whereas PHD1 and PHD2 are able to hydroxylate both CODD and NODD prolines, but have higher affinity for the NODD. ${ }^{39,40}$ The implications of this remain enigmatic. When hydroxylated, these prolines on HIF- $\alpha$ serve as binding sites for the von Hipple-Lindau ubiquitin ligase, leading to ubiquitination and degradation of HIF- $\alpha$ (Figure 5).

Conversely, when $\mathrm{O}_{2}$ is limited (hypoxia) PHD enzymes are less active, leading to increased HIF- $\alpha$ stability and nuclear localization. ${ }^{41}$ In the nucleus, HIF- $\alpha$ dimerizes with the constitutively expressed HIF- $\beta$ /aryl hydrocarbon receptor nuclear translocator nuclear subunit. ${ }^{42,43}$ The HIF- $\alpha /$ HIF $\beta$ heterodimer (collectively termed HIF) binds to deoxyribonucleic acid (DNA) on 5'(A/G)CGTG-3' sequences called hypoxia response elements (HRE), and recruits p300/CBP to its C-terminal transactivation domain, leading to transcriptional transactivation of HIF target genes. ${ }^{43,44}$ HIF target genes are numerous, and include enzymes of the glycolytic pathway, vascular endothelial growth factor, as well as PHD2 and PHD3. ${ }^{37,45,46}$ Collectively, upregulated HIF target genes act synergistically to increase energy production in the absence of $\mathrm{O}_{2}$ and to restore vascular supply by stimulating vascular recruitment and vessel growth. ${ }^{37}$ For an overview of the HIF pathway and its control by PHD enzymes, see Figure 6.

\section{Regulation of PHD3 expression and localization}

Of the three PHD enzymes, PHD3 is the most dynamic with regard to its expression, localization, and stability. Interestingly, $\mathrm{O}_{2}$ levels control each of these parameters. The following will discuss these unique regulatory properties of PHD3.

\section{Control of PHD3 transcription}

\section{PHD3 induction by hypoxia}

The induction of PHD3 expression by hypoxia is exquisite. A study performed by Appelhoff et a ${ }^{40}$ nicely demonstrates this property. Here, relative expression levels of the three PHD enzymes were analyzed over ten human cancer cell lines. While PHD3 expression during normoxia is the lowest

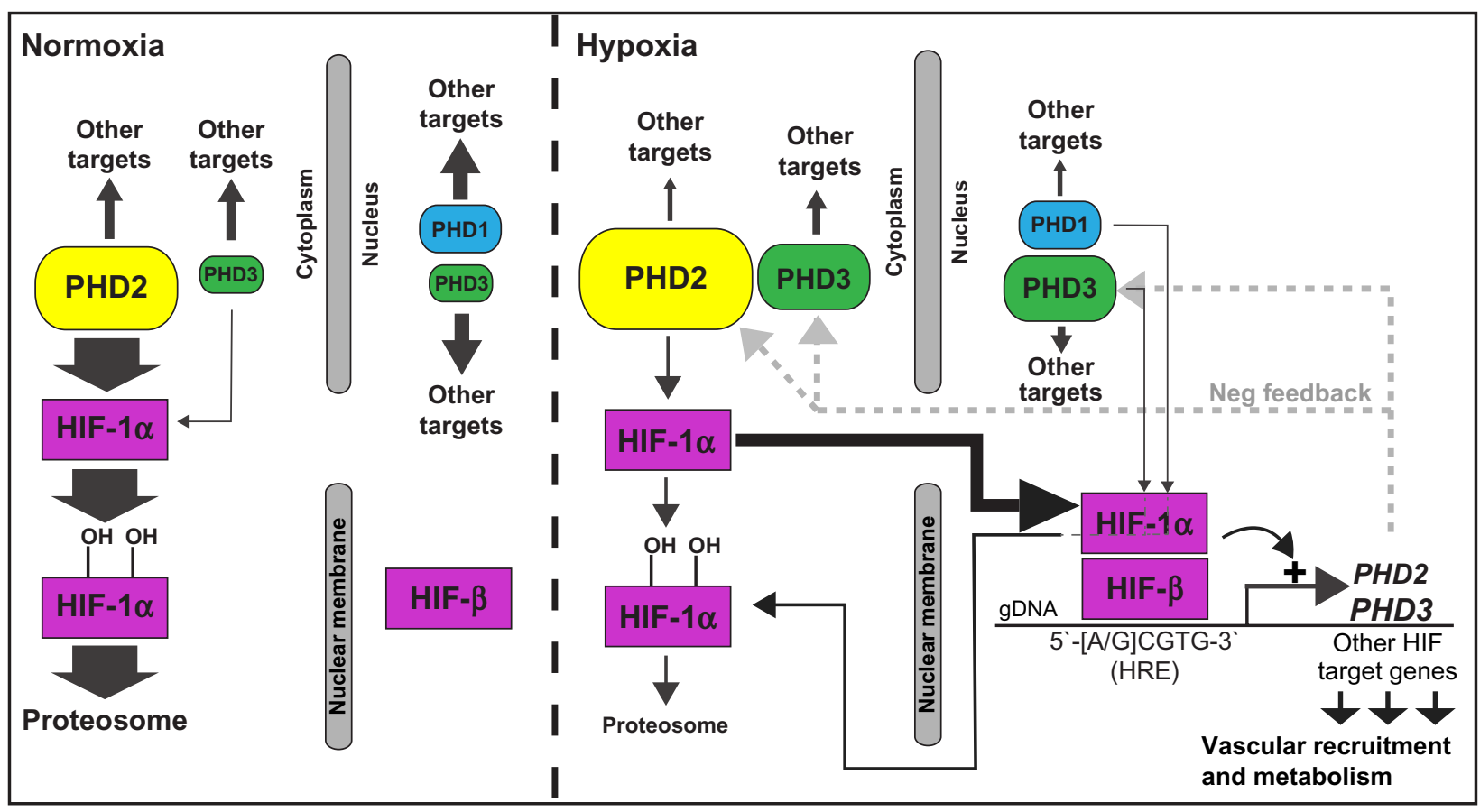

Figure 6 HIF pathway regulation by the PHD enzymes.

Notes: HIF-I can be a substrate for any of the three PHD proteins; however, PHD3, which is the most inducible PHD under hypoxic conditions, has broader substrate specificity and can hydroxylate a number of non-HIF-I $\alpha$ targets.

Abbreviations: PHD, prolyl-4-hydroxylase; HIF, hypoxia-inducible transcription factor; OH, hydroxyl group; gDNA, genomic deoxyribonucleic acid; HRE, hypoxia response elements; Neg, negative. 

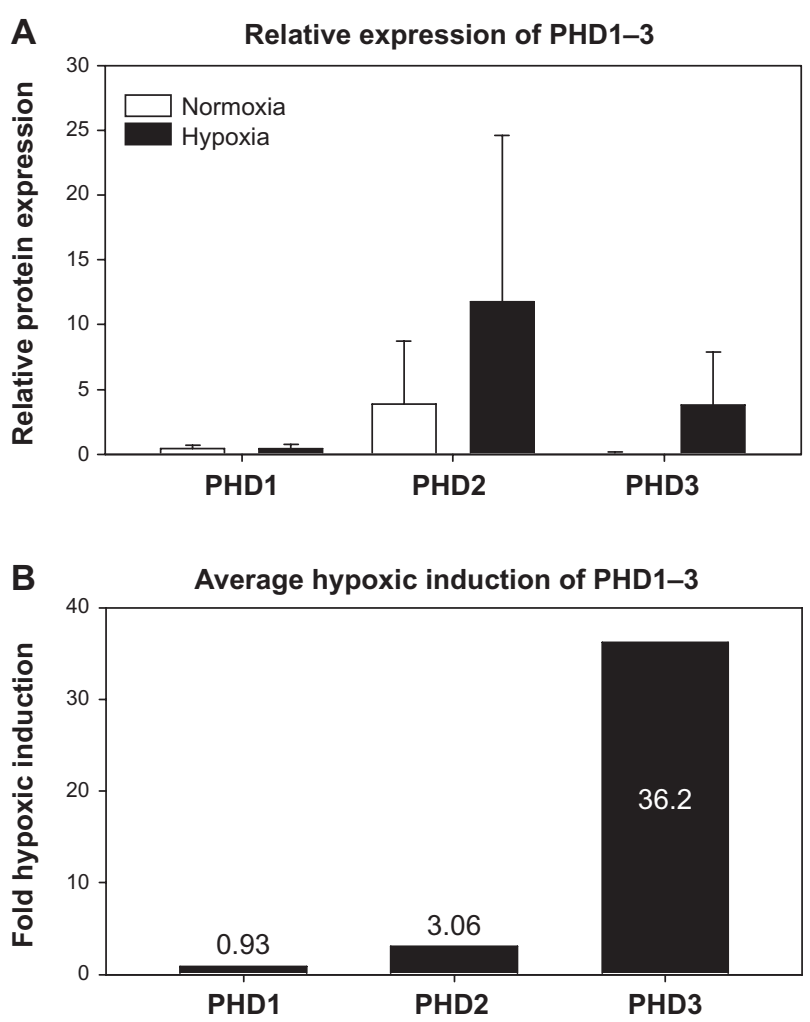

Figure 7 Relative expression of PHDI, PHD2, and PHD3 in ten human cancer cell lines.

Notes: The relative expression of PHD enzymes was determined by Appelhoff et al ${ }^{40}$ in ten human cancer cell lines: U2-OS, BxPC3, MCF7, ZR75I, MDA-435, BT-474, HEP3B, HeLa, 833K, and SuSa cell lines under normoxic and hypoxic $\left(1 \% \mathrm{O}_{2}\right)$ conditions for 16 hours. (A) Appelhoff et al's ${ }^{40}$ data were recompiled and averaged to demonstrate general trends in the relative expression of PHDI, PHD2, and PHD3. Error bars represent one standard deviation. (B) The average fold hypoxicinduction of each PHD is re-graphed from the data above ${ }^{\wedge} 40$.

Abbreviation: PHD, prolyl-4-hydroxylase. of the three PHDs, it is induced by an average of 36.2-fold after 16 hours in $1 \% \mathrm{O}_{2}$. This is compared to only a threefold induction of PHD2, and no hypoxic induction of PHD1 (relative expression data from Appelhoff et $\mathrm{al}^{40}$ has been summarized, including statistical analysis, and are displayed in Figure 7). At the messenger ribonucleic acid level, PHD3 upregulation by hypoxia occurs by binding of HIF to an HRE, resulting in transcriptional transactivation. ${ }^{46,47}$ Although there are numerous HRE consensus sequences throughout the PHD3 gene, HIF binding under hypoxic conditions has been demonstrated to occur at a specific site in intron 1 approximately $+12.5 \mathrm{~kb}$ downstream of the transcription start site. ${ }^{46-48}$ When analyzed at the nucleotide base level using the University of California Santa Cruz Genome Browser (GRCH37/ hg19), three HRE elements are present in this region, along with conserved binding sites for Pax2, Hand1/E47, and nuclear factor-1 (Figure 8). ${ }^{49,50}$ Due to the close proximity of these three HREs, it is unclear which is utilized by HIF- $1 \alpha$. However, these HREs overlap the Hand1/E47 and nuclear factor-1 sites, suggesting that occupancy of these sites could affect HIF binding to the region. Indeed, evidence suggests that stress response transcription factors (including Hand1/ E47) are overrepresented in regions containing functional HREs, and may "fine tune" the hypoxia-induced expression at the gene level. ${ }^{48}$

The importance of the $+12.5 \mathrm{~kb}$ region of PHD3 in transcriptional control can be seen in polymerase 2 ( $\mathrm{Pol} 2$ ) ChIP-seq data mining analysis. Several Pol 2 ChIP-seq

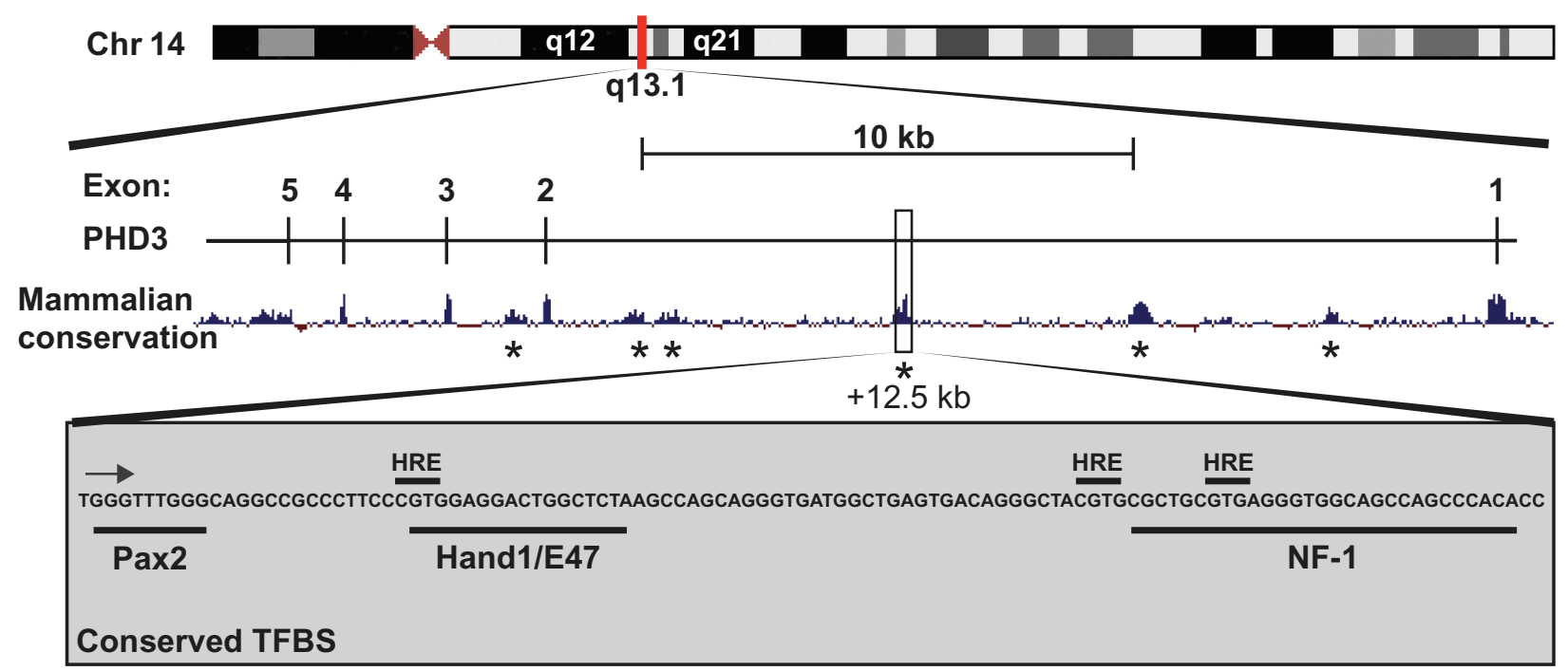

Figure 8 PHD3 regulatory elements.

Notes: The PHD3 gene with mammalian conservation is depicted in relation to its position on chromosome 14 q13.I (modified from the UCSC Genome Browser hgl9 [http://genome.ucsc.edu/]). ${ }^{49}$ The highly conserved region at $\sim+12 \mathrm{~kb}$ upstream of exon $\mathrm{I}$ is expanded (bottom), and putative HRE are indicated (gray box), along with conserved TF binding sites, as predicted by the UCSC hgl9 “TFBS conserved" track. The black arrow indicates the direction of 3 ' -5 ' sequence orientation. *Represents highly conserved sequences located in intron I and 2 that may represent important regulatory regions.

Abbreviations: Chr, chromosome; PHD, prolyl-4-hydroxylase; HRE, hypoxia response elements; NF-I, nuclear factor-I; TF, transcription factor; UCSC, University of California Santa Cruz; TFBS, transcription factor binding sites. 

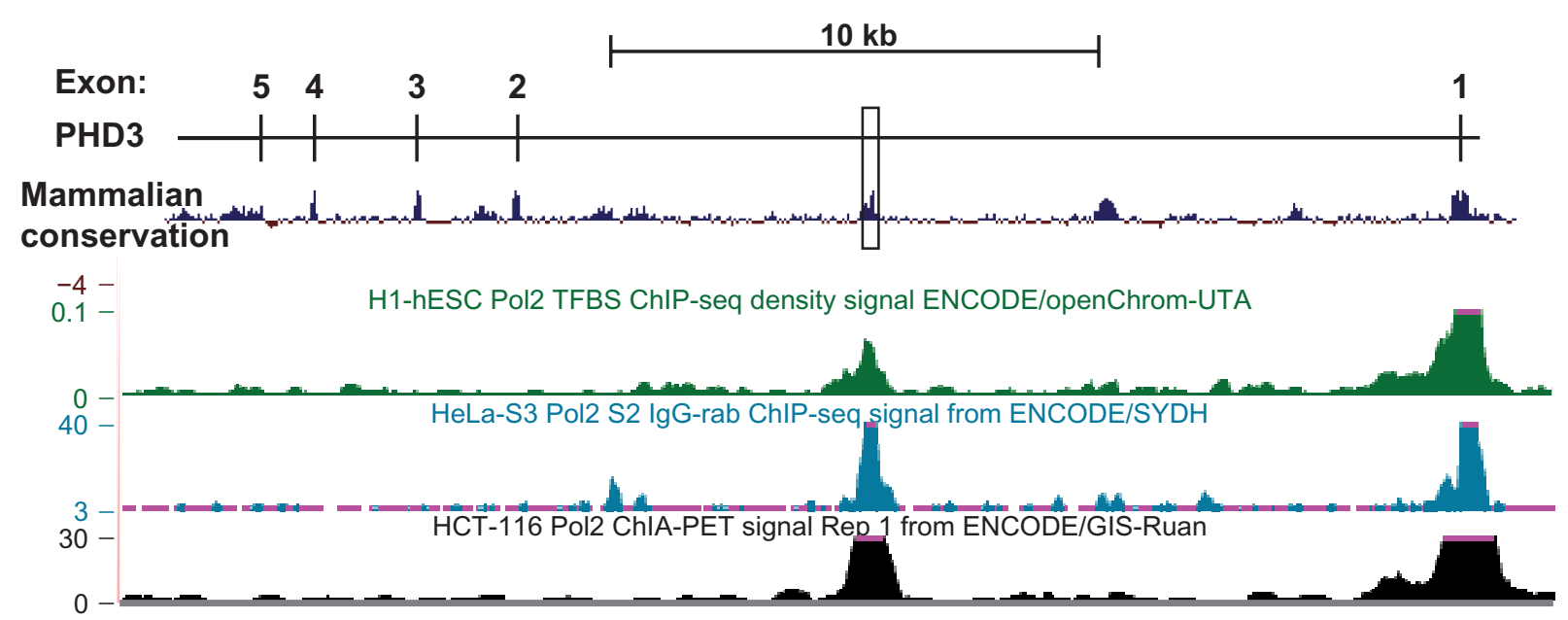

Figure 9 Polymerase 2 interaction with +12 kb region of the PHD3 gene.

Notes: The PHD3 locus is represented with mammalian conservation (modified from the UCSC Genome Browser hgl9 [http://genome.ucsc.edu/]). ${ }^{49}$ ChIP-Seq signal data for polymerase 2 in HI-hESC, HeLa-S3, and HCT-II6 cells were mined from several ENCODE data tracks (as indicated) using the UCSC Genome Browser hgI 9 (http:// genome.ucsc.edu/). ${ }^{50}$

Abbreviations: PHD, prolyl-4-hydroxylase; hESC, human embryonic stem cells; TFBS, transcription factor binding sites; ENCODE, Encyclopedia of DNA Elements; ChIA$\mathrm{PET}$, chromatin interaction analysis with paired-end tag sequencing; ChIP-Seq, chromatin immunoprecipitation sequencing.

tracks in the University of California Santa Cruz Genome Browser (GRCH37/hg19) indicate a biphasic Pol 2 signal at both the $P H D 3$ promoter and $+12 \mathrm{~kb}$ region in intron 1 (Figure 9). ${ }^{49,50}$ This does not appear to occur in PHD1 and PHD2, and to our knowledge, the significance of this has not yet been demonstrated. However, it does not appear to be associated with an alternative transcriptional start site, as no alternative transcripts have been published to originate in this region. This may represent a "poised" normoxic state where chromosomal looping creates a physical association of the promoter and HRE containing $+12 \mathrm{~kb}$ region. Upon hypoxic stimulation, HIF binding to this region could stimulate activation of Pol 2 transcription. Experiments that combine Pol 2 and HIF-1 $\alpha$ ChIP-seq under both normoxic and hypoxic conditions would provide significant insight into the mechanisms surrounding the induction of PHD3 transcription by hypoxia.

The precise role(s) for PHD3 upregulation under hypoxic conditions is not clear. However, in the context of the HIF pathway, evidence suggests that it plays a predominant role in regulating HIF- $2 \alpha .^{40}$ Here, it may act similarly to the PHD2-HIF-1 $\alpha$ feedback loop that has been nicely demonstrated in experiments by Millonig et al. ${ }^{51}$ These authors demonstrate that acute induction of hypoxia leads to a transient rise in HIF- $1 \alpha$ protein expression. Following a brief time period, these levels subsequently return back to baseline despite continued hypoxia. This can be attributed to hypoxia-induced PHD2 protein expression, which enables cells to effectively increase HIF- $1 \alpha$ hydroxylation under lower $\mathrm{O}_{2}$ concentrations. When PHD2 activity is eliminated by colbalt chloride treatment, HIF-1 $\alpha$ levels remain high rather than returning to baseline. ${ }^{51}$

Another function of PHD3 upregulation during hypoxia may be to control metabolism. Remarkably, PHD3 has been demonstrated to interact with the M2-isoform of pyruvate kinase, altering both the flux of carbons through glycolysis and the regulation of metabolic gene expression via interaction with HIF. $30,52,53$

\section{Hypoxia-independent regulation of PHD3}

Aside from the pronounced regulatory control of PHD3 by hypoxia and HIF-1 $\alpha$, PHD3 transcriptional regulation by other factors has been extensively described. However, most of these experiments were performed in the rat, where PHD3 was first discovered. ${ }^{54}$ This initial characterization placed PHD3 in the realm of immediate-early genes. These immediate-early genes are responsive to rapid transcriptional upregulation by the growth agonists platelet-derived growth factor angiotensin 2 and serum, and are not inhibited at the transcriptional level by cyclohexamide (protein synthesis inhibitor) ${ }^{54}$ Here, the induction of $P H D 3$ by serum appears dependent on an SP1/SP3 binding site in the proximal PHD3 promoter. ${ }^{55}$ In murine myeloid $32 \mathrm{D}$ cells, $P H D 3$ is also induced by c-Myc, which is known to synergize with SP1/ SP3 to promote transcription. ${ }^{56}$ In endothelial cells, PHD3 can be induced downstream of interferon- $\gamma$ in a JAK/STAT1dependent manner. ${ }^{57}$ Other, larger studies focusing on global transcriptional changes downstream of specific stimuli have indicated that PHD3 may be induced by mechanism involving p53 in rat fibroblasts, and via signaling downstream of 
nerve growth factor (NGF) withdrawal in rat neurons, where PHD3 appears to mediate apoptosis. . $5,58,59$

Another regulatory layer controlling the expression of PHD3 is DNA methylation. We have previously demonstrated that several human cancer cell lines of diverse tissue origin silence PHD3 expression in a DNA methylationdependent manner. ${ }^{60}$ PHD3 promoter methylation has also been demonstrated in primary human B-cell malignancies. ${ }^{61}$ The fact that PHD3 is silenced in such a wide variety of tumor types suggests that PHD3 affects important signaling pathways that are common to the progression of many malignancies.

\section{Regulation of PHD3 expression via alternative splicing}

A final, and less well-addressed mechanism by which PHD3 expression can be controlled by the cell is alternative splicing. Following transcription of $P H D 3$, at least three transcripts of varying size can be detected in many tissues and cell lines. ${ }^{62}$ These represent full-length PHD3, a form missing half of exon 1 (PHD3 $\Delta 1)$, and a form in which exon 4 is missing (PHD3 44$){ }^{62}$ To our knowledge, no one has yet detected endogenous alternative transcripts that are translated to proteins; however, forced expression of these isoforms by expression vectors does result in detectable protein of the appropriate reduced molecular weight. Furthermore, it appears that the PHD3 $\Delta 4$ isoform retains hydroxylase activity, whereas PHD3 $\Delta 1$ is hydroxylase deficient. ${ }^{62}$ It will be interesting to see what, if any, role these alternative transcripts play in cell signaling.

\section{Control of PHD3 protein stability}

In cell line studies under normoxic conditions, PHD3 protein levels are maintained at levels significantly below that of PHD1 and PHD2 (Figure 7). ${ }^{40}$ However, during periods of hypoxia, PHD3 protein levels are remarkably increased. Although some of this regulation occurs via transcriptional control, a significant portion is a result of increased PHD3 protein stability under hypoxic conditions. The mechanism for this appears to be mediated by the E3 ubiquitin ligase Siah2. ${ }^{34,63}$ Under normoxia, the PHD3 protein is present in small molecular weight fractions that represent homomultimers of the PHD3 protein. These small complexes of PHD3 appear to be enzymatically active, but also accessible to Siah2mediated ubiquitination, followed by degradation. In hypoxia, PHD3 forms larger molecular weight complexes consisting of heteromultimers of PHD3 with other PHD proteins. In this form, PHD3 is not accessible to Siah2 for ubiquitination. ${ }^{34}$

\section{Control of PHD3 localization}

Another unique aspect of PHD3 regulation is its subcellular localization. Whereas PHD1 and PHD2 are expressed almost exclusively in the nucleus and cytoplasm respectively, PHD3 is expressed both in the nucleus and cytoplasm. ${ }^{27,64}$ Furthermore, in the presence of plentiful $\mathrm{O}_{2}$, PHD3 appears to be largely sequestered in aggregates that colocalize with the proteasome. ${ }^{35}$ The mechanism of this aggregation is unknown, but may affect the hydroxylation potential, proapoptotic activity, as well as the Siah2-mediated PHD3 degradation, as discussed above..$^{34,35}$

Interestingly, the localization of rat PHD3 (smooth muscle-20) differs from that of other mammals. This is likely due to the evolution of a large N-terminal sequence containing a mitochondrial localization sequence. ${ }^{59}$ Evidence suggests that this mitochondrial targeting sequence becomes cleaved in a fraction of rat PHD3, allowing cytoplasmic/ nuclear localization similar to that of other mammals. ${ }^{59}$ The exact function of the rat PHD3 mitochondrial localization sequence, or if there is a functional difference between rat PHD3 and PHD3 of other mammals, is not known. Nevertheless, because of this additional protein localization motif in rats, caution should be used when interpreting PHD3 data from rat cells, as these data may be qualitatively different from the human PHD3 phenotype.

\section{PHD3 function}

Although the PHDs were originally characterized for their control of the HIF pathway, PHD3 does not appear to be a major player in HIF regulation under nonstressed conditions. This is evident in mouse studies, where embryos of $\mathrm{PHD}^{-/-}$ mice do not show abnormalities in the placenta, an organ critically dependent on the HIF pathway for normal development. ${ }^{65,66}$ In fact, $P H D 3^{-/-}$mice appear grossly normal in the absence of any insults and survive normally into adulthood. ${ }^{65}$ In contrast, $\mathrm{PHD}^{-/-}$embryos die between day 12.5 and day 14.5 of embryonic development, and display an abnormal placenta, with significantly increased levels of HIF- $1 \alpha$, HIF- $2 \alpha$, and vascular endothelial growth factor protein expression upon immunohistochemical examination. ${ }^{65}$

Even though these data do not show a major role for PHD3 in normal developmental processes that involve the HIF pathway, there is evidence that PHD3 does regulate HIF-2 $\alpha$ during hypoxia followed by reoxygenation in cancer cell lines. ${ }^{40}$ This may signify that PHD3 plays more of a role in regulating the HIF pathway during pathological processes that involve hypoxia and/or hypoxia-reoxygenation (ischemia/ reperfusion). Although evidence supporting this hypothesis 
is limited, a recent study has shown that $P H D 3^{-/-}$mice have an aberrant response to infection, which can produce regions of tissue hypoxia due to inadequate perfusion. ${ }^{67}$ The extent to which this PHD3-related phenotype is related to PHD3's effects on the hypoxia-response pathway, as opposed to its effects on other non-HIF signaling pathways, remains to be determined.

As suggested above, there are numerous publications that describe a role for PHD3 in non-HIF signaling pathways (see following sections for specific citations). These include, but are not limited to control of sympathetic neuronal development, myogenic signaling, cell migration, metabolism, and cell survival. The following will discuss the evidence for PHD3 in cell signaling mechanisms that fall outside of HIF pathway regulation.

\section{Muscle development, differentiation, and survival}

PHD3 appears to have an important relationship to muscle. In fact, upon PHD3's initial discovery by Wax et al in $1994,{ }^{54}$ it was named smooth muscle-20. Wax proceeded to report high expression of PHD3 in smooth, skeletal, and cardiac muscle (as well as in brain and nerve cells), with no detectable transcript in fibroblasts. ${ }^{54}$ Interestingly, PHD3 expression in these cells was upregulated in response to the vasoactive growth factors angiotensin 2 and platelet-derived growth factor, and this expression was not inhibited by pretreatment by cyclohexamide. Therefore, PHD3 was categorized as an immediate early gene in rat vascular smooth muscle. ${ }^{54}$ Thirteen years later, the role of PHD3 expression in muscle cells was elaborated; Fu et al ${ }^{68,69}$ demonstrated that PHD3 promotes myogenic differentiation in part through its stabilization of myogenin and inhibition of nuclear factorkappa beta signaling during skeletal muscle myogenesis. Others have described a proapoptotic role for PHD3 in rat embryonic heart-derived $\mathrm{H} 9 \mathrm{c} 2$ cells and neonatal rat ventricular cardiomyocytes. ${ }^{70,71}$ Here, PHD3 was found to induce apoptosis in response to stress in the form of doxorubicin or hypoxia-reoxygenation. Knockdown of PHD3 (by small interfering ribonucleic acid or by endogenous miR-20a), or inhibition of PHD hydroxylase activity appeared to mitigate the PHD3 proapoptotic response..$^{70,71}$

\section{Immune system function}

$\mathrm{PHD}^{-/-}$mice display marked defects in immune system function. Specifically, knockout mice produce a hyperimmune response to septic stimuli that includes increased recruitment of macrophages to internal organs, and increased proinflammatory cytokine production. ${ }^{67}$ This phenotype is specific for the loss of PHD3, as $\mathrm{PHD}^{-/-}$and $\mathrm{PHD}^{+/-}$mice are normal in this regard. Furthermore, this effect is specific to the innate immune system, as sublethal irradiation of wild type mice, followed by bone marrow transplant from $\mathrm{PHD}^{-/}$mice results in a similar hyperimmune response to sepsis. ${ }^{67}$ In vivo experiments indicate that PHD3 expression is a predominant feature of proinflammatory macrophages, and PHD3 loss appears to result in an increased macrophage migratory and phagocytic capacity. ${ }^{67,72}$ Thus, PHD3 expression appears, in part, to limit the proinflammatory response of macrophages to pathogens.

PHD3 also appears to play a key role in neutrophil survival. ${ }^{73} \mathrm{PHD}^{-/}$mice have reduced neutrophilic inflammation in models of lipopolysaccharide-induced acute lung injury and dextran sodium sulfate-induced colitis. This was attributed to the decreased survival of $\mathrm{PHD}^{-/-}$neutrophils due to hypoxic conditions that are present within these areas of inflammation. ${ }^{73}$ Furthermore, the effects of PHD knockout on hypoxic survival were confirmed in in vitro experiments, where $\mathrm{PHD}^{-/-}$neutrophils underwent an increase in apoptosis under hypoxic laboratory conditions. ${ }^{73}$

\section{Cell motility/migration}

A possible role for proline hydroxylation in cell motility can be found in studies of the slime mold, D. discoideum, which use $\mathrm{O}_{2}$ gradients to direct cell motility into more favorable environments. ${ }^{74}$ This function could likely be downstream of $\mathrm{O}_{2}$ sensing by a PHD that is evolutionarily related to mammalian PHD1-3 enzymes., ${ }^{5,7}$ In mammals, the literature also supports a more specific role for PHD3 in the regulation of cell motility and cytoskeletal dynamics. $\mathrm{PHD}^{-/-}$neurons have an apparent defect in axon guidance, where $P H D 3$ loss resulted in increased axonal growth and branching. ${ }^{75}$ In another report, knockout of PHD3 was shown to result in an exacerbated macrophage-mediated immune response to abdominal sepsis. ${ }^{67}$ This was characterized by an increased migratory capacity of $\mathrm{PHD}^{-/-}$macrophages. ${ }^{67}$ A similar effect of PHD3 loss can be found in cancer cells, as knockdown of PHD3 was shown to result in an increase in cell invasion through Matrigel ${ }^{\mathrm{TM}}$ (BD Biosciences, San Jose, CA, USA) in human pancreatic adenocarcinoma cell lines. ${ }^{76}$

\section{Regulation of survival and apoptotic pathways}

Many studies demonstrate a clear role for PHD3 in the regulation of both cell survival and apoptotic pathways. Much of 
Table I List of PHD3-targets and interacting proteins along with the methods used

\begin{tabular}{|c|c|c|}
\hline $\begin{array}{l}\text { PHD3 target/ } \\
\text { interacting } \\
\text { protein }\end{array}$ & $\begin{array}{l}\text { Method for } \\
\text { determining } \\
\text { interaction }\end{array}$ & $\begin{array}{l}\text { Method for } \\
\text { determining } \\
\text { hydroxylation }\end{array}$ \\
\hline $\begin{array}{l}\text { hCLK2 (P374, P4I9, } \\
\text { P422) }\end{array}$ & $\begin{array}{l}\text { Co-IP }(E+O E) \\
\text { GST-PD }\end{array}$ & $\begin{array}{l}\text { LC-MS/MS with } \\
\text { peptide }\end{array}$ \\
\hline PKM2 (P403, P408) & Co-IP (OE); GST-PD & $\begin{array}{l}\text { Orbitrap LC-MS; } \\
\text { HP-Ab }\end{array}$ \\
\hline $\mathrm{PKM} 2^{53}$ & Co-IP (E); GST-PD & $\mathrm{N} / \mathrm{A}$ \\
\hline$\beta 2-A R(P 382, P 395)^{31}$ & Co-IP (OE); GST-PD & LC-MS/MS \\
\hline hPRPI $9^{87}$ & $\begin{array}{l}\text { Co-IP }(E+O E) \\
\text { GST-PD }\end{array}$ & N/A \\
\hline IKK $\beta^{88}$ & $\begin{array}{l}\text { Co-IP }(E+O E) \\
\text { GST-PD }\end{array}$ & $\mathrm{N} / \mathrm{A}$ \\
\hline Morg190 & $\begin{array}{l}\text { Co-IP (IVTT proteins); } \\
\text { Co-IP (OE) }\end{array}$ & $\mathrm{N} / \mathrm{A}$ \\
\hline Siah $2^{34}$ & Co-IP (OE); GST-PD & $\mathrm{N} / \mathrm{A}$ \\
\hline $\mathrm{Bcl}-2^{70}$ & Co-IP (OE) & $\mathrm{N} / \mathrm{A}$ \\
\hline $\begin{array}{l}\text { Proteosome } \\
(20 \mathrm{~S} \text { core })^{35}\end{array}$ & Colocalization by IF & $\mathrm{N} / \mathrm{A}$ \\
\hline ATF-4' & $\begin{array}{l}\text { Y2HB; Co-IP } \\
\text { (OE in insect cells) }\end{array}$ & $N / A$ \\
\hline OS-992 & Co-IP (OE) & $\mathrm{N} / \mathrm{A}$ \\
\hline MAGE-I I 93 & Co-IP (OE) & $\mathrm{N} / \mathrm{A}$ \\
\hline $\mathrm{TRiC}^{94}$ & Co-IP (OE) & $\mathrm{N} / \mathrm{A}$ \\
\hline $\mathrm{PHD}^{34}$ & Co-IP (OE) & N/A \\
\hline $\mathrm{PHD}^{34}$ & Co-IP (OE) & N/A \\
\hline $\mathrm{PHDI}^{34}$ & Co-IP (OE) & N/A \\
\hline
\end{tabular}

Notes: Column I lists all non-HIF proteins known to be targets of and/or that interact with PHD3. The specific prolines targeted for hydroxylation are listed (if applicable). Column 2 lists the methods used to determine the interaction of each protein with PHD3. GST-PD use purified proteins (unless otherwise noted). For the peptide, isotope-labeled synthetic hydroxylated peptide was used as a control. For N/A, some publications demonstrated that the hydroxylase mutant PHD3 had same effect as PHD3-wild type, and therefore did not assay for hydroxylation of the interacting protein.

Abbreviations: PHD, prolyl-4-hydroxylase; Co-IP, coimmunoprecipitation; E, endogenous proteins; OE, overexpressed proteins; GST-PD, GST-pulldown experiments using purified proteins; LC, liquid chromatography; MS, mass spectrometry; PKM2, pyruvate kinase isoenzyme; HP-Ab, hydroxyproline antibody; N/A, not attempted; IKK $\beta$, IkappaB kinase beta; IVTT, in vitro translated and transcribed proteins; IF, immunofluorescence; ATF-4, AMP-dependent transcription factor 4; Y2HB, yeast 2 hybrid; MAGE-II, melanoma antigen gene protein-AII; HIF, hypoxia-inducible transcription factor; S, subunit; hCLK2, TEL2/telmomere maintenance 2; hPRP19, preRNA processing factor 19 homolog (of S. cerevisiae); Bcl, B-Cell lymphoma; OS-9, osteosarcoma amplified 9.

this research, however, has been done in the context of rat PC12 (pheochromocytoma) cells and primary rat sympathetic neurons. As discussed in this review, rat PHD3 contains a large N-terminal sequence and mitochondrial localization signal that is not present in other mammals. Due to this property, it is difficult to translate some of the results of these studies into humans. (Table 2 provides a comprehensive list of studies involving experiments on the prosurvival and proapoptotic effects of PHD3). Aside from the structural differences between rat and human PHD3, some of the apparent disparities of PHD3's effects on cell survival appear to be due, in part, to its functional dependency on $\mathrm{O}_{2}$. In fact, many of these studies report a requirement for PHD3-enzymatic activity for its proapoptotic effects. Therefore, it seems likely that PHD3's role in apoptosis or survival is at least partially dependent on the presence or absence of $\mathrm{O}_{2}$, respectively.

\section{Prosurvival studies}

Although demonstrations of PHD3's proapoptotic effects are found in a vast majority of PHD3 studies, these effects have been shown to play a prosurvival role under hypoxic conditions in several cell types. In head and neck carcinoma cells, PHD3 appears to promote cell cycle progression from the G1-S phase..$^{77}$ One mechanism for this increased survival under hypoxia may be due to PHD3's effects on cell metabolism. Both PHD3 and pyruvate kinase M2 isoform have been shown to complex with nuclear HIF-1 $\alpha$, promoting the transcription of genes involved in glycolysis under hypoxic conditions. ${ }^{30}$ This may allow for increased adenosine triphosphate production through the glycolytic pathway when $\mathrm{O}_{2}$ is limiting. Another study similarly showed an interaction between pyruvate kinase $\mathrm{M} 2$ isoform and PHD3 in the cytosol, where the complex appears to regulate the flux of carbons through glycolysis. ${ }^{53}$ Thus, PHD3 may act to promote survival under hypoxic conditions both indirectly (promoting transcription of metabolic genes) and directly (by modulating metabolic processes themselves).

The role of PHD3 in hypoxic cell survival is also evident from studies of PHD3 expression from tumor samples. Here, PHD3 is often upregulated compared to its expression in normal tissue. ${ }^{76,78-81}$ The high expression of PHD3 in these samples suggests that it is not acting to induce apoptosis. In fact, PHD3 expression was correlated with increased aggressiveness in pancreatic exocrine and endocrine cancers. However, it was not determined whether PHD3 expression was the reason for this increase in aggressiveness, or if the correlation was simply due to the presence of tumor hypoxia, which upregulates PHD3 expression. Regardless, these studies suggest that upregulation of PHD3 under hypoxic conditions in some cancers does not result in apoptosis, but rather may promote tumor progression and/or survival.

\section{Proapoptotic studies}

Despite the evidence of PHD3's prosurvival attributes, evidence for proapoptotic functions dominates the PHD3 literature. In fact, one of the major phenotypes discovered in $\mathrm{PHD}^{-/-}$mice was due to a decrease of PHD3-mediated apoptosis in neurons during sympathoadrenal development. ${ }^{75}$ Overall, this resulted in enlarged sympathetic ganglia and reduced target tissue innervation. ${ }^{75}$ Indeed, several studies 
Table 2 List of publications relevant to PHD3 and cell survival

\begin{tabular}{|c|c|c|c|c|}
\hline Effector & $\begin{array}{l}\text { Hydroxy- } \\
\text { dependent? }\end{array}$ & Major conclusion & Cell type & Year Ref \\
\hline $\mathrm{hCLK}^{\Psi}$ & Yes & $\begin{array}{l}\text { PHD3 promotes activation of the DNA damage response } \\
\text { through hydroxylation of } \mathrm{hCLK} 2 \text { following ionizing radiation }\end{array}$ & MEFs and mouse thymus & $2012^{29}$ \\
\hline $\mathrm{PKM}^{\Psi}$ & Yes & $\begin{array}{l}\text { PHD3 promotes metabolic reprogramming under hypoxia } \\
\left(1 \% \mathrm{O}_{2}\right) \text { through its interaction with PKM2 and HIF }\end{array}$ & HeLa (cervical cancer) & $2011^{30}$ \\
\hline Unknown & No & $\begin{array}{l}\text { PHD3 expression enhances cell cycle progression and } \\
\text { overall cell-survival during prolonged hypoxia }\left(1 \% \mathrm{O}_{2}\right)\end{array}$ & $\begin{array}{l}\text { UT-SCC 2,7,8,9,33 (head and } \\
\text { neck squamous cell carcinoma) }\end{array}$ & $201 I^{77}$ \\
\hline Unknown & Unknown & $\begin{array}{l}\text { PHD3 expression is negatively correlated with } \mathrm{Bcl}-2 \\
\text { expression, and positively correlated with advanced stage } \\
\text { and poor differentiation }\end{array}$ & Nonsmall cell lung cancer & $201 I^{78}$ \\
\hline Unknown & Yes & $\begin{array}{l}\text { PHD3 } 3^{-/} \text {neutrophils show reduced hypoxic survival } \\
\text { compared to neutrophils from PHD3 wild type mice }\end{array}$ & Primary mouse neutrophils & $201 I^{73}$ \\
\hline hPRPI9 & Unknown & $\begin{array}{l}\text { hPRPI9 interacts with PHD3 and inhibits PHD3-mediated } \\
\text { apoptosis under prolonged hypoxia }\left(1 \% \mathrm{O}_{2}\right)\end{array}$ & Rat PCI2 (pheochromocytoma) & $2010^{87}$ \\
\hline IKK $\beta$ & No & $\begin{array}{l}\text { PHD3 inhibits NFKB activity through association with } \\
\text { IKK } \beta \text { - preventing IKK } \beta \text { phosphorylation; PHD3 } \\
\text { expression negatively correlates with colorectal tumor } \\
\text { grade and metastasis }\end{array}$ & $\begin{array}{l}\text { HCT-I I6, SW480 (colorectal } \\
\text { cancer), human colorectal cancer } \\
\text { specimens }\end{array}$ & $2010^{88}$ \\
\hline Unknown & Yes* & $\begin{array}{l}\text { Esterified 2-OG induces apoptosis in xenografts - } \\
\text { dependent on PHD3 expression }\end{array}$ & $\begin{array}{l}\text { HCT-II6 (colon carcinoma), } \\
\text { A43I (SSC), A375 (melanoma) }\end{array}$ & $2010^{89}$ \\
\hline Unknown & Yes* & $\begin{array}{l}\text { PHD3 overexpression induces caspase } 3 \text { cleavage in the } \\
\text { presence of } \mathrm{O}_{2} \text {. DMOG inhibits this effect. }\end{array}$ & $\begin{array}{l}\text { MiaPaca2, Pancl (pancreatic } \\
\text { adenocarcinoma) }\end{array}$ & $2010^{76}$ \\
\hline $\mathrm{Bcl}-2$ & Yes & $\begin{array}{l}\text { PHD3 expression promotes apoptosis by interacting with } \\
\mathrm{Bcl}-2 \text { to prevent } \mathrm{Bcl}-2 / \mathrm{Bax} \text { complex on mitochondria }\end{array}$ & H9c2 (rat cardiomyoblast) & $2010^{70}$ \\
\hline KIFIB $\beta$ & Unknown & $\begin{array}{l}\text { KIFIB } \beta \text { acts downstream of PHD3 to induce } \\
\text { apoptosis in neural-crest derived cells but not } \\
\text { cells derived from kidney or fibroblasts }\end{array}$ & $\begin{array}{l}\text { PCI2 (rat pheochromocytoma), } \\
\text { SK-Mel28 (melanoma) }\end{array}$ & $2008^{84}$ \\
\hline Unknown & Yes & $\begin{array}{l}\text { PHD3 expression induces } 20 \mathrm{~S} \text { proteosomal } \\
\text { aggregation and apoptosis in an } \mathrm{O}_{2} \text {-dependent } \\
\text { manner }\end{array}$ & HeLa (cervical cancer) & $2008^{35}$ \\
\hline Unknown & Unknown & $\begin{array}{l}\text { NGF withdrawal from sympathetic neurons } \\
\text { results in c-jun-mediated PHD3 upregulation and } \\
\text { PHD3-induced apoptosis }\end{array}$ & PCI2 (rat pheochromocytoma) & $2005^{82}$ \\
\hline Unknown & Unknown & $\begin{array}{l}\text { PHD3 expression stimulates cytochrome C release } \\
\text { in neuronal cells but not HEK293 or CV-I cells }\end{array}$ & $\begin{array}{l}\text { Rat PCI2 (pheochromocytoma) } \\
\text { and neonatal sympathetic } \\
\text { neuronal cells }\end{array}$ & $2003^{83}$ \\
\hline Unknown & Unknown & $\begin{array}{l}\text { PHD3 expression induces caspase- } 3 \text { dependent } \\
\text { apoptosis downstream of cytochrome } \mathrm{c} \text { release }\end{array}$ & $\begin{array}{l}\text { Rat primary embryonic } \\
\text { sympathetic neurons }\end{array}$ & $200 I^{59}$ \\
\hline Unknown & Unknown & $\begin{array}{l}\text { PHD3 induces neuronal cell death following NGF } \\
\text { withdrawal }\end{array}$ & $\begin{array}{l}\text { Rat primary embryonic } \\
\text { sympathetic neurons }\end{array}$ & 199925 \\
\hline
\end{tabular}

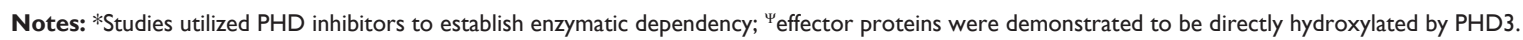

Abbreviations: PHD3, prolyl-4-hydroxylase; Ref, reference; DNA, deoxyribonucleic acid; MEF, mouse embryonic firbroblasts; PKM2, Pyruvate kinase isoenzyme; HIF, hypoxia-inducible transcription factor; UT-SCC, ; PCI2, pheochromocytoma I2; IKK $\beta$, IkappaB kinase beta; NFKB, nuclear factor-kappa beta; 2-OG, 2-oxolglutarate; SSC, spermatogonial stem cells; DMOG, dimethyloxalylglycine; NGF, nerve growth factor; S, subunit; hCLK2, TEL2/telmomere maintenance 2; hPRPI9, pre-RNA processing factor 19 homolog (of S. cerevisiae); Bcl, B-Cell lymphoma; KIFIB, kinesin family member IB.

have demonstrated a significant increase in PHD3 transcript levels following the withdrawal of NGF from cultures of neuronally-derived cell lines. ${ }^{25,82,83}$ In particular, NGF withdrawal from the rat pheochromocytoma cell line, PC12, results in a c-jun-dependent upregulation of PHD3, followed by cytochrome c release and caspase-dependent cell death. ${ }^{83}$ It has also been proposed that the kinesin KIF1B $\beta$ may act downstream of PHD3 to mediate these proapoptotic effects. ${ }^{84}$ $\mathrm{KIF} 1 \mathrm{~B} \beta$ acts as a molecular motor, and is responsible for synaptic vesicle transport. It is difficult to hypothesize precisely how KIF1B $\beta$ might modulate cell survival in this regard. Clearly more work must be done in this area.

The clear role for PHD3 in neuronal apoptosis predicts that PHD3 mutation may be involved in the progression of neuronal malignancies. To date, however, PHD3 mutations have not been reported in any type of malignancy. On the other hand, inhibition of PHD3 activity through other mechanisms may contribute to survival of cancer cells in this disease. For example, SDH mutations are common in pheochromocytoma. ${ }^{82}$ These mutations lead to a buildup of 
succinate, which can inhibit PHD3 activity through product inhibition of the hydroxylation reaction. ${ }^{13,82}$ Similarly, gain-offunction mutations in IDH result in the abnormal production of 2-HG, which also inhibits PHD activity in some gliomas. ${ }^{85}$ The idea that PHD3 inhibition due to mutations in TCA enzymes acts as a driving force for these types of malignancies is an exciting proposition; however, the precise mechanism remains fairly obscure and warrants further research.

Outside of neurons, PHD3 also has proapoptotic effects. It is purported to interact with $\mathrm{Bcl}-2$, inhibiting the formation of the antiapoptotic Bax-Bcl-2 complex in muscle cells. ${ }^{70}$ However, PHD3 has also been demonstrated to promote apoptosis through hydroxylation of the human biological clock protein 2 (hCLK2), which in turn promotes apoptosis through activation of the ATR-Chk1-P53 DNA damage response pathway following ionizing radiation. ${ }^{29}$ In the HeLa cervical cancer cell line, transfection of a green fluorescent proteinPHD3 vector in normoxic conditions induced PHD3 localization into large punctate cytoplasmic aggregates followed by apoptosis. ${ }^{35}$ These "aggresomes" colocalized with the $20 \mathrm{~S}$ proteasome and were associated with caspase- 3 cleavage and apoptosis. ${ }^{35}$ This process appeared to require $\mathrm{O}_{2}$ (and thus PHD3-enzymatic activity) as inhibition of PHD3 with the 2-OG analog dimethyloxalylglycine, and mutation of PHD3, caused a more diffuse cytoplasmic localization, which protected cells from the proapoptotic effects of PHD $3 .{ }^{35}$ Whether PHD3's interaction with "aggresomes", Bcl-2, and hCLK2 are related, or are cell-type/stimulus dependent remains to be elucidated. Nonetheless, PHD3-mediated apoptosis appears to require molecular $\mathrm{O}_{2}$ and hydroxylase activity.

\section{Conclusion}

Over the last 2 billion years, molecular $\mathrm{O}_{2}$ has accumulated and persisted on Earth. Its presence has promoted many functions of life, including the evolution of aerobic respiration. However, it has also antagonized life through its capacity to oxidize and inactivate biological molecules. The evolution of the prolyl-hydroxylase was an evolutionary answer to the antagonistic effects of $\mathrm{O}_{2}$, providing the cell with a tool to sense and adapt to changes in $\mathrm{O}_{2}$ concentration.

The proline-hydroxylation reaction itself requires $\mathrm{O}_{2}$ and 2-OG, and the PHD catalytic core contains a Fe-2 atom that is sensitive to oxidation by ROS. This allows tight integration of cell signaling with $\mathrm{O}_{2}$ concentration, TCA cycle function, and oxidative stress in the cell. Predictably, an enzyme with this sensitivity to react simultaneously to an array of metabolic cues should be involved in a broad array of cell signaling processes.
In the case of PHD3, a plethora of recent literature is beginning to support such roles. In fact, data argue that PHD3 is involved in cell differentiation, death, survival, and metabolism. Furthermore, PHD3 expression may modulate complex processes such as cell migration and immune system function, providing a direct link between $\mathrm{O}_{2}$ and these important biological processes. There is no doubt that continued research into the functions of PHD3 and other proline hydroxylases will continue to evolve our understanding of the intimate link between $\mathrm{O}_{2}$ sensing and cell signaling.

\section{Disclosure}

The authors report no conflicts of interest in this work.

\section{References}

1. Taylor CT, McElwain JC. Ancient atmospheres and the evolution of oxygen sensing via the hypoxia-inducible factor in metazoans. Physiology (Bethesda). 2010;25(5):272-279.

2. Catling DC, Claire MW. How Earth's atmosphere evolved to an oxic state: a status report. Earth Planet Sci Lett. 2006;237(1-2):1-20.

3. Holland HD. The oxygenation of the atmosphere and oceans. Philos Trans R Soc Lond B Biol Sci. 2006;361(1470):903-915.

4. Parfrey LW, Lahr DJ, Knoll AH, Katz LA. Estimating the timing of early eukaryotic diversification with multigene molecular clocks. Proc Natl Acad Sci U S A. 2011;108(33):13624-13629.

5. West CM, van der Wel H, Wang ZA. Prolyl 4-hydroxylase-1 mediates O2 signaling during development of Dictyostelium. Development. 2007;134(18):3349-3358.

6. Hughes BT, Espenshade PJ. Oxygen-regulated degradation of fission yeast SREBP by Ofd1, a prolyl hydroxylase family member. EMBOJ. 2008;27(10):1491-1501.

7. Rytkönen KT, Williams TA, Renshaw GM, Primmer CR, Nikinmaa M. Molecular evolution of the metazoan PHD-HIF oxygen-sensing system. Mol Biol Evol. 2011;28(6):1913-1926.

8. Myllyharju J. Prolyl 4-hydroxylases, the key enzymes of collagen biosynthesis. Matrix Biol. 2003;22(1):15-24.

9. Koivunen P, Tiainen P, Hyvärinen J, et al. An endoplasmic reticulum transmembrane prolyl 4-hydroxylase is induced by hypoxia and acts on hypoxia-inducible factor alpha. J Biol Chem. 2007;282(42): 30544-30552.

10. Cardinale GJ, Rhoads RE, Udenfriend S. Simultaneous incorporation of $18 \mathrm{O}$ into succinate and hydroxyproline catalyzed by collagen proline hydroxylase. Biochem Biophys Res Commun. 1971;43(3):537-543.

11. Pollard PJ, Brière JJ, Alam NA, et al. Accumulation of Krebs cycle intermediates and over-expression of HIF1alpha in tumours which result from germline FH and SDH mutations. Hum Mol Genet. 2005;14(15): 2231-2239.

12. Dang L, Jin S, Su SM. IDH mutations in glioma and acute myeloid leukemia. Trends Mol Med. 2010;16(9):387-397.

13. Maxwell PH. A common pathway for genetic events leading to pheochromocytoma. Cancer Cell. 2005;8(2):91-93.

14. Tuderman L, Myllylä R, Kivirikko KI. Mechanism of the prolyl hydroxylase reaction. 1. Role of co-substrates. Eur J Biochem. 1977;80(2): 341-348.

15. Schofield CJ, Ratcliffe PJ. Signalling hypoxia by HIF hydroxylases. Biochem Biophys Res Commun. 2005;338(1):617-626.

16. Spitz DR, Azzam EI, Li JJ, Gius D. Metabolic oxidation/reduction reactions and cellular responses to ionizing radiation: a unifying concept in stress response biology. Cancer Metastasis Rev. 2004;23(3-4):311-322.

17. Guzy RD, Hoyos B, Robin E, et al. Mitochondrial complex III is required for hypoxia-induced ROS production and cellular oxygen sensing. Cell Metab. 2005;1(6):401-408. 
18. Kaewpila S, Venkataraman S, Buettner GR, Oberley LW. Manganese superoxide dismutase modulates hypoxia-inducible factor-1 alpha induction via superoxide. Cancer Res. 2008;68(8):2781-2788.

19. Myllylä R, Kuutti-Savolainen ER, Kivirikko KI. The role of ascorbate in the prolyl hydroxylase reaction. Biochem Biophys Res Commun. 1978;83(2):441-448.

20. Peterkofsky B. Ascorbate requirement for hydroxylation and secretion of procollagen: relationship to inhibition of collagen synthesis in scurvy. Am J Clin Nutr. 1991;54(Suppl 6):1135S-1140S.

21. Hoffart LM, Barr EW, Guyer RB, Bollinger JM, Krebs C. Direct spectroscopic detection of a C-H-cleaving high-spin Fe(IV) complex in a prolyl-4-hydroxylase. Proc Natl Acad Sci U S A. 2006;103(40): 14738-14743.

22. Knowles HJ, Raval RR, Harris AL, Ratcliffe PJ. Effect of ascorbate on the activity of hypoxia-inducible factor in cancer cells. Cancer Res. 2003;63(8):1764-1768.

23. Pagé EL, Chan DA, Giaccia AJ, Levine M, Richard DE. Hypoxiainducible factor-1alpha stabilization in nonhypoxic conditions: role of oxidation and intracellular ascorbate depletion. Mol Biol Cell. 2008;19(1):86-94.

24. Ho VT, Bunn HF. Effects of transition metals on the expression of the erythropoietin gene: further evidence that the oxygen sensor is a heme protein. Biochem Biophys Res Commun. 1996;223(1):175-180.

25. Lipscomb EA, Sarmiere PD, Crowder RJ, Freeman RS. Expression of the SM-20 gene promotes death in nerve growth factor-dependent sympathetic neurons. J Neurochem. 1999;73(1):429-432.

26. Epstein AC, Gleadle JM, McNeill LA, et al. C. elegans EGL-9 and mammalian homologs define a family of dioxygenases that regulate HIF by prolyl hydroxylation. Cell. 2001;107(1):43-54.

27. Huang J, Zhao Q, Mooney SM, Lee FS. Sequence determinants in hypoxia-inducible factor-1alpha for hydroxylation by the prolyl hydroxylases PHD1, PHD2, and PHD3. J Biol Chem. 2002;277(42): 39792-39800.

28. Li D, Hirsilä M, Koivunen P, et al. Many amino acid substitutions in a hypoxia-inducible transcription factor (HIF)-1alpha-like peptide cause only minor changes in its hydroxylation by the HIF prolyl 4-hydroxylases: substitution of 3,4-dehydroproline or azetidine-2-carboxylic acid for the proline leads to a high rate of uncoupled 2-oxoglutarate decarboxylation. J Biol Chem. 2004;279(53):55051-55059.

29. Xie L, Pi X, Mishra A, Fong G, Peng J, Patterson C. PHD3-dependent hydroxylation of HCLK2 promotes the DNA damage response. $J$ Clin Invest. 2012;122(8):2827-2836.

30. Luo W, Hu H, Chang R, et al. Pyruvate kinase M2 is a PHD3-stimulated coactivator for hypoxia-inducible factor 1. Cell. 2011;145(5): 732-744.

31. Xie L, Xiao K, Whalen EJ, et al. Oxygen-regulated beta(2)-adrenergic receptor hydroxylation by EGLN3 and ubiquitylation by pVHL. Sci Signal. 2009;2(78):ra33.

32. Kivirikko KI, Myllylä R. Posttranslational enzymes in the biosynthesis of collagen: intracellular enzymes. Meth Enzymol. 1982;82 Pt A: 245-304.

33. Stadtman ER. Oxidation of free amino acids and amino acid residues in proteins by radiolysis and by metal-catalyzed reactions. Annu Rev Biochem. 1993;62:797-821.

34. Nakayama K, Gazdoiu S, Abraham R, Pan ZQ, Ronai Z. Hypoxiainduced assembly of prolyl hydroxylase PHD3 into complexes: implications for its activity and susceptibility for degradation by the E3 ligase Siah2. Biochem J. 2007;401(1):217-226.

35. Rantanen K, Pursiheimo J, Högel H, Himanen V, Metzen E, Jaakkola PM. Prolyl hydroxylase PHD3 activates oxygen-dependent protein aggregation. Mol Biol Cell. 2008;19(5):2231-2240.

36. Semenza GL. HIF-1: upstream and downstream of cancer metabolism. Curr Opin Genet Dev. 2010;20(1):51-56.

37. Semenza GL. Oxygen homeostasis. Wiley Interdiscip Rev Syst Biol Med. 2010;2(3):336-361

38. Semenza GL. Regulation of oxygen homeostasis by hypoxia-inducible factor 1. Physiology (Bethesda). 2009;24:97-106.
39. Villar D, Vara-Vega A, Landázuri MO, Del Peso L. Identification of a region on hypoxia-inducible-factor prolyl 4-hydroxylases that determines their specificity for the oxygen degradation domains. Biochem $J$. 2007;408(2):231-240.

40. Appelhoff RJ, Tian YM, Raval RR, et al. Differential function of the prolyl hydroxylases PHD1, PHD2, and PHD3 in the regulation of hypoxia-inducible factor. J Biol Chem. 2004;279(37):38458-38465.

41. Kallio PJ, Okamoto K, O’Brien S, et al. Signal transduction in hypoxic cells: inducible nuclear translocation and recruitment of the $\mathrm{CBP} /$ p300 coactivator by the hypoxia-inducible factor-1alpha. EMBO J. 1998; 17(22):6573-6586.

42. Wang GL, Jiang BH, Rue EA, Semenza GL. Hypoxia-inducible factor 1 is a basic-helix-loop-helix-PAS heterodimer regulated by cellular $\mathrm{O} 2$ tension. Proc Natl Acad Sci U S A. 1995;92(12):5510-5514.

43. Wang GL, Semenza GL. Purification and characterization of hypoxiainducible factor 1. J Biol Chem. 1995;270(3):1230-1237.

44. Arany Z, Huang LE, Eckner R, et al. An essential role for p300/ CBP in the cellular response to hypoxia. Proc Natl Acad Sci U S A. 1996;93(23):12969-12973.

45. Metzen E, Stiehl DP, Doege K, Marxsen JH, Hellwig-Bürgel T, Jelkmann W. Regulation of the prolyl hydroxylase domain protein 2 (phd2/egln1) gene: identification of a functional hypoxia-responsive element. Biochem J. 2005;387(Pt 3):711-717.

46. Pescador N, Cuevas Y, Naranjo S, et al. Identification of a functional hypoxia-responsive element that regulates the expression of the egl nine homologue 3 (egln3/phd3) gene. Biochem J. 2005;390(Pt 1): 189-197.

47. Schödel J, Oikonomopoulos S, Ragoussis J, Pugh CW, Ratcliffe PJ, Mole DR. High-resolution genome-wide mapping of HIF-binding sites by ChIP-seq. Blood. 2011;117(23):e207-e217.

48. Villar D, Ortiz-Barahona A, Gómez-Maldonado L, et al. Cooperativity of stress-responsive transcription factors in core hypoxia-inducible factor binding regions. PLoS ONE. 2012;7(9):e45708.

49. Meyer LR, Zweig AS, Hinrichs AS, et al. The UCSC Genome Browser database: extensions and updates 2013. Nucleic Acids Res. 2013;41(Database issue):D64-D69.

50. Rosenbloom KR, Sloan CA, Malladi VS, et al. ENCODE data in the UCSC Genome Browser: year 5 update. Nucleic Acids Res. 2013;41(Database issue):D56-D63

51. Millonig G, Hegedüsch S, Becker L, Seitz HK, Schuppan D, Mueller S. Hypoxia-inducible factor 1 alpha under rapid enzymatic hypoxia: cells sense decrements of oxygen but not hypoxia per se. Free Radic Biol Med. 2009;46(2):182-191.

52. Luo W, Semenza GL. Pyruvate kinase M2 regulates glucose metabolism by functioning as a coactivator for hypoxia-inducible factor 1 in cancer cells. Oncotarget. 2011;2(7):551-556.

53. Chen N, Rinner O, Czernik D, et al. The oxygen sensor PHD3 limits glycolysis under hypoxia via direct binding to pyruvate kinase. Cell Res. 2011;21(6):983-986.

54. Wax SD, Rosenfield CL, Taubman MB. Identification of a novel growth factor-responsive gene in vascular smooth muscle cells. $J$ Biol Chem. 1994;269(17):13041-13047.

55. Menzies K, Liu B, Kim WJ, Moschella MC, Taubman MB. Regulation of the SM-20 prolyl hydroxylase gene in smooth muscle cells. Biochem Biophys Res Commun. 2004;317(3):801-810.

56. Kyo S, Takakura M, Taira T, et al. Sp1 cooperates with c-Myc to activate transcription of the human telomerase reverse transcriptase gene (hTERT). Nucleic Acids Res. 2000;28(3):669-677.

57. Gerber SA, Yatsula B, Maier CL, Sadler TJ, Whittaker LW, Pober JS. Interferon-gamma induces prolyl hydroxylase (PHD)3 through a STAT1dependent mechanism in human endothelial cells. Arterioscler Thromb Vasc Biol. 2009;29(9):1363-1369.

58. Madden SL, Galella EA, Riley D, Bertelsen AH, Beaudry GA. Induction of cell growth regulatory genes by p53. Cancer Res. 1996;56(23): 5384-5390.

59. Lipscomb EA, Sarmiere PD, Freeman RS. SM-20 is a novel mitochondrial protein that causes caspase-dependent cell death in nerve growth factordependent neurons. J Biol Chem. 2001;276(7):5085-5092. 
60. Place TL, Fitzgerald MP, Venkataraman S, et al. Aberrant promoter CpG methylation is a mechanism for impaired PHD3 expression in a diverse set of malignant cells. PLoS ONE. 2011;6(1):e14617.

61. Hatzimichael E, Dasoula A, Shah R, et al. The prolyl-hydroxylase EGLN3 and not EGLN1 is inactivated by methylation in plasma cell neoplasia. Eur J Haematol. 2010;84(1):47-51.

62. Cervera AM, Apostolova N, Luna-Crespo F, Sanjuan-Pla A, Garcia-Bou R, McCreath KJ. An alternatively spliced transcript of the PHD3 gene retains prolyl hydroxylase activity. Cancer Lett 2006;233(1):131-138.

63. Nakayama K, Frew IJ, Hagensen M, et al. Siah2 regulates stability of prolyl-hydroxylases, controls HIF1alpha abundance, and modulates physiological responses to hypoxia. Cell. 2004;117(7): 941-952.

64. Metzen E, Berchner-Pfannschmidt U, Stengel P, et al. Intracellular localisation of human HIF-1 alpha hydroxylases: implications for oxygen sensing. J Cell Sci. 2003;116(Pt 7):1319-1326.

65. Takeda K, Ho VC, Takeda H, Duan LJ, Nagy A, Fong GH. Placental but not heart defects are associated with elevated hypoxia-inducible factor alpha levels in mice lacking prolyl hydroxylase domain protein 2. Mol Cell Biol. 2006;26(22):8336-8346.

66. Dunwoodie SL. The role of hypoxia in development of the Mammalian embryo. Dev Cell. 2009;17(6):755-773.

67. Kiss J, Mollenhauer M, Walmsley SR, et al. Loss of the oxygen sensor PHD3 enhances the innate immune response to abdominal sepsis. J Immunol. 2012;189(4):1955-1965.

68. Fu J, Menzies K, Freeman RS, Taubman MB. EGLN3 prolyl hydroxylase regulates skeletal muscle differentiation and myogenin protein stability. J Biol Chem. 2007;282(17):12410-12418.

69. Fu J, Taubman MB. Prolyl hydroxylase EGLN3 regulates skeletal myoblast differentiation through an NF-kappaB-dependent pathway. J Biol Chem. 2010;285(12):8927-8935.

70. Liu Y, Huo Z, Yan B, et al. Prolyl hydroxylase 3 interacts with Bcl-2 to regulate doxorubicin-induced apoptosis in $\mathrm{H} 9 \mathrm{c} 2$ cells. Biochem Biophys Res Commun. 2010;401(2):231-237.

71. Frank D, Gantenberg J, Boomgaarden I, et al. MicroRNA-20a inhibits stress-induced cardiomyocyte apoptosis involving its novel target Egln3/ PHD3. J Mol Cell Cardiol. 2012;52(3):711-717.

72. Escribese MM, Sierra-Filardi E, Nieto C, et al. The prolyl hydroxylase PHD3 identifies proinflammatory macrophages and its expression is regulated by activin A. J Immunol. 2012;189(4):1946-1954.

73. Walmsley SR, Chilvers ER, Thompson AA, et al. Prolyl hydroxylase 3 (PHD3) is essential for hypoxic regulation of neutrophilic inflammation in humans and mice. J Clin Invest. 2011;121(3):1053-1063.

74. Sternfeld J, David CN. Oxygen gradients cause pattern orientation in Dictyostelium cell clumps. J Cell Sci. 1981;50:9-17.

75. Bishop T, Gallagher D, Pascual A, et al. Abnormal sympathoadrenal development and systemic hypotension in PHD3-/- mice. Mol Cell Biol. 2008;28(10):3386-3400.

76. Su Y, Loos M, Giese N, et al. PHD3 regulates differentiation, tumour growth and angiogenesis in pancreatic cancer. $\mathrm{Br}$ J Cancer. 2010;103(10):1571-1579.

77. Högel H, Rantanen K, Jokilehto T, Grenman R, Jaakkola PM. Prolyl hydroxylase PHD3 enhances the hypoxic survival and G1 to S transition of carcinoma cells. PLoS ONE. 2011;6(11):e27112.

Hypoxia

\section{Publish your work in this journal}

Hypoxia is an international, peer-reviewed, open access journal that aims to improve understanding of the biological response to hypoxia. The journal will publish original research articles, reviews, methodological advances, clinical studies, and expert opinions that identify developments in the regulation of the physiological and pathological responses

Submit your manuscript here: http://www.dovepress.com/hypoxia-journal
78. Chen S, Zhang J, Li X, Luo X, Fang J, Chen H. The expression of prolyl hydroxylase domain enzymes are up-regulated and negatively correlated with Bcl-2 in non-small cell lung cancer. Mol Cell Biochem. 2011;358(1-2):257-263.

79. Su C, Huang K, Sun L, et al. Overexpression of the HIF hydroxylase PHD3 is a favorable prognosticator for gastric cancer. Med Oncol. 2012;29(4):2710-2715.

80. Couvelard A, Deschamps L, Rebours V, et al. Overexpression of the oxygen sensors PHD-1, PHD-2, PHD-3, and FIH Is associated with tumor aggressiveness in pancreatic endocrine tumors. Clin Cancer Res. 2008;14(20):6634-6639.

81. Gossage L, Zaitoun A, Fareed KR, et al. Expression of key hypoxia sensing prolyl-hydroxylases PHD1, -2 and -3 in pancreaticobiliary cancer. Histopathology. 2010;56(7):908-920.

82. Lee S, Nakamura E, Yang H, et al. Neuronal apoptosis linked to EgIN3 prolyl hydroxylase and familial pheochromocytoma genes: developmental culling and cancer. Cancer Cell. 2005;8(2):155-167.

83. Straub JA, Lipscomb EA, Yoshida ES, Freeman RS. Induction of SM-20 in PC12 cells leads to increased cytochrome c levels, accumulation of cytochrome $\mathrm{c}$ in the cytosol, and caspase-dependent cell death. J Neurochem. 2003;85(2):318-328.

84. Schlisio S, Kenchappa RS, Vredeveld LC, et al. The kinesin KIF1Bbeta acts downstream from EgIN3 to induce apoptosis and is a potential 1p36 tumor suppressor. Genes Dev. 2008;22(7):884-893.

85. Dang L, White DW, Gross S, et al. Cancer-associated IDH1 mutations produce 2-hydroxyglutarate. Nature. 2009;462(7274):739-744.

86. Bruick RK, McKnight SL. A conserved family of prolyl-4-hydroxylases that modify HIF. Science. 2001;294(5545):1337-1340.

87. Sato M, Sakota M, Nakayama K. Human PRP19 interacts with prolylhydroxylase PHD3 and inhibits cell death in hypoxia. Exp Cell Res. 2010;316(17):2871-2882.

88. Xue J, Li X, Jiao S, Wei Y, Wu G, Fang J. Prolyl hydroxylase-3 is downregulated in colorectal cancer cells and inhibits IKKbeta independent of hydroxylase activity. Gastroenterology. 2010;138(2):606-615.

89. Tennant DA, Gottlieb E. HIF prolyl hydroxylase-3 mediates alphaketoglutarate-induced apoptosis and tumor suppression. $\mathrm{J} \mathrm{Mol} \mathrm{Med.}$ 2010;88(8):839-849.

90. Hopfer U, Hopfer H, Jablonski K, Stahl RA, Wolf G. The novel WD-repeat protein Morg1 acts as a molecular scaffold for hypoxia-inducible factor prolyl hydroxylase 3 (PHD3). J Biol Chem. 2006;281(13):8645-8655.

91. Köditz J, Nesper J, Wottawa M, et al. Oxygen-dependent ATF-4 stability is mediated by the PHD3 oxygen sensor. Blood. 2007;110(10): 3610-3617.

92. Baek JH, Mahon PC, Oh J, et al. OS-9 interacts with hypoxia-inducible factor 1alpha and prolyl hydroxylases to promote oxygen-dependent degradation of HIF-1alpha. Mol Cell. 2005;17(4):503-512.

93. Aprelikova O, Pandolfi S, Tackett S, et al. Melanoma antigen-11 inhibits the hypoxia-inducible factor prolyl hydroxylase 2 and activates hypoxic response. Cancer Res. 2009;69(2):616-624.

94. Masson N, Appelhoff RJ, Tuckerman JR, et al. The HIF prolyl hydroxylase PHD3 is a potential substrate of the TRiC chaperonin. FEBS Lett. 2004;570(1-3):166-170.

to hypoxia and in the therapeutic targeting of hypoxia-responsive pathways. The manuscript management system is completely online and includes a very quick and fair peer-review system, which is all easy to use. Visit http://www.dovepress.com/testimonials.php to read real quotes from published authors.

\section{Dovepress}

